\title{
New Wind-Wave Climate Records in the Western Mediterranean Sea
}

Khalid AMAROUCHE ( $\square$ khalidamarouche@uludag.edu.tr)

Bursa Uludağ Üniversitesi: Bursa Uludag Universitesi https://orcid.org/0000-0001-7983-4611

\section{Bilal Bingölbali}

Bursa Uludağ Üniversitesi: Bursa Uludag Universitesi

\section{Adem Akpinar}

Bursa Uludağ Üniversitesi: Bursa Uludag Universitesi

\section{Research Article}

Keywords: Wave climate, Climate change, Climate records, Coastal storm, Climate change trends, Mediterranean climate

Posted Date: July 12th, 2021

DOl: https://doi.org/10.21203/rs.3.rs-689001/v1

License: (c) (i) This work is licensed under a Creative Commons Attribution 4.0 International License. Read Full License

Version of Record: A version of this preprint was published at Climate Dynamics on November 3rd, 2021. See the published version at https://doi.org/10.1007/s00382-021-05997-1. 


\section{New wind-wave climate records in the Western Mediterranean Sea}

(1)

Khalid Amarouche ${ }^{\text {a }, *}$, Bilal Bingölbali ${ }^{\text {a }}$, Adem Akpinar ${ }^{\text {a }}$

${ }^{a}$ Bursa Uludag University, Department of Civil Engineering, Gorukle Campus, Bursa, Turkey

\section{Abstract}

This study presents a detailed analysis of changes in wind and wave climate in the Western Mediterranean Sea (WMed), based on 41 years of accurate wind and wave hindcasts. The purpose of this research is to assess the magnitude of recent changes in wave climate and to locate the coastal areas most affected by these changes. Starting from the Theil-Sen slope estimator and the Mann Kendall test, trends in mean and Max significant wave heights (SWH) and wind speed (WS) are analyzed simultaneously on seasonal and annual scales. Thus, the new wave records observed since 2010 have been located spatially and temporally using a simple spatial analysis method, while the increases in maximum wave heights over the last decade have been estimated and mapped. This work was motivated by evidence pointed out by several authors concerning the influence of global climate change on the local climate in the Mediterranean Sea and by the increase in the number and intensity of wave storm events over recent years. Several exceptional storms have recently been observed along the Mediterranean coasts, including storm Adrian in 2018 and storm Gloria in 2020, which resulted in enormous damage along the French and Spanish coasts. The results of the present study reflect a worrying situation in a large part of the WMed coasts. Most of the WMed basin experiences a significant increasing trend in the annual Max of SWH and WS with evident inter-seasonal variability that underlines the importance of multi-scale analysis to assess wind and wave trends. Since 2013, about half of the WMed coastline has experienced records in wave climate, not recorded at least since 1979, and several areas have experienced three successive records. Several WMed coasts are experiencing a worrying evolution of the wave climate, which requires a serious mobilization to prevent probable catastrophic wave storms and ensure sustainable and economic development.

Keywords: Wave climate; Climate change; Climate records; Coastal storm; Climate change trends; Mediterranean climate.

*: Corresponding author: Amarouche Khalid, Tel.: +213696985659 .

E-mail: amarouchekhalid@gmail.com , kh.amarouche@enssmal.dz, Fax:/. +90 2242941903 , Address: Uludağ Üniversitesi İnşaat Mühendisliği Bölümü, Görükle Kampüs-Nilüfer, 16059, Turquie. orcid.org/0000-0001-7983-4611.1 


\section{Introduction}

In January 2020, the storm Gloria reached a new record of significant wave heights (SWH) observed by wave measuring buoys located in the Northern part of the WMed. The wave heights measured by the Tarragona buoy, located approximately $1.1 \mathrm{~km}$ from the coast at $15 \mathrm{~m}$ depth, have exceeded for the first time the $4 \mathrm{~m}$ height since its installation in 1992. This storm was responsible for considerable human and material losses on the French and Spanish coasts. In addition to the storm Gloria, several other catastrophic wave storm events have recently been recorded on the African and European coasts, including the Adrian storm in October 2018 (Csekits and Troisi 2018; Cavaleri et al. 2019), caused serious damages in the French and Italian coasts and ports. Evidence of changes in wave climate and an increase in the coastal storm intensity in recent decades has recently been reported by several researchers, both at the global (Gulev 2004; Mori et al. 2010; Reguero et al. 2019) and regional (Casas-Prat and Sierra 2011; Burden et al. 2020; Vieira et al. 2020; Amarouche and Akpinar 2021) scales. The researchers have suggested that serious consideration should be accorded to the risks and probable damage that such coastal storms may induce in the near and far future. According to a recent study by Tuel and Eltahir (2020), the Mediterranean Sea has been identified as a climate change hotspot for the coming decades. The significant trends, mostly increasing, have been observed in several Mediterranean regions for several parameters (Geeson et al. 2002), including air temperature (Sánchez et al. 2004; Lionello and Scarascia 2020), precipitation (Sánchez et al. 2004; Ulbrich et al. 2006), sea surface temperature (Pisano et al. 2020), sea level (Taibi and Haddad 2019), wind speed (Soukissian et al. 2018), wave surge (Garcia-Herrera et al. 2014) and SWH (De Leo et al. 2020). Since winds represent the main force responsible for the generation of gravitational waves, the study of both wind and wave variations can provide important information on several parameters related to climate dynamics. Wind wave variations are conditioned by variations in WS, wind persistence, wind direction, fetch distance, and fetch area; hence a significant change in wind-wave climate is associated with a variation in all of these parameters and which are also related to changes in atmospheric pressure and air temperatures. The generation of extreme waves height is often linked to extreme weather conditions.

In the present study, we elaborate a detailed assessment of the changes in wave climates observed during the last 41 years in the WMed, and those focusing on the trends of mean and Max SWH, mean and Max WS, and on the last records of Max SWH observed during the last decade. This study, as recommended by Casas-Prat and Sierra (2011), is based on high spatialand temporal resolution $\left(0.033^{\circ}\right.$ at both directions and three hours) hindcasted wave data, 
developed using the nearshore wave model SWAN (Booij et al. 1999; Ris et al. 1999), which was calibrated particularly for the WMed Sea by Amarouche et al., (2019). Thus, these data were complemented by wave buoy measurements and satellite altimeter observation data for an accurate estimation of trends in SWH and new wave records. The Theil-Sen non-parametric method of trend estimation was adopted, and the Mann Kendal non-parametric test was applied for the estimation of the trend significance level. Thus, for the determination and quantification of new records of SWH observed between 2010 and 2020, a spatial comparison between the Max SWH observed between 2010 and 2020 and the maximum wave heights observed since 1979 was performed. The results identify coastal hotspots in the WMed region experiencing high wind and wave climate variability. The location of these hotspots allows anticipating more precautionary measures against future scenarios of wave storms that may induce catastrophic damages.

\section{Methodology}

Knowledge of extreme wind and wave climate events and their trends in the areas of coastal and offshore activities, ports, tourism, maritime transport, renewable energy farms, aquaculture is often essential to ensure sustainable, safe, and economic development of these activities, e.g., according to Cramer et al., (2018) policies for the sustainable development of the Mediterranean countries; particularly the southern countries, do not have adequate options for good management of the risks linked to the climate change acceleration. In this study, we are interested in the remarkable change in the wind-wave climate and in the new records of wave climate observed in the WMed Sea during the last decade, and we focus mainly on the spatial variation of the annual trends of Max SWH and simultaneously to the trend of the force responsible for their generation which is the WS, and those in order to understand the spatial relationship between the trends of WS and wave heights, and also the spatial connection of both parameters' trends, with respect to the new records of extreme SWH. A wave trend study based on 40-year wave data published by De Leo et al., (2020) shows that a large part of the Spanish coasts that were highly exposed to record waves during the storm Gloria did not have a significant trend of Max SWH (SWH_Max), thus, according to the results of Yuchun and Leo, (2020) an area characterized by a WS trend may not have a significant trend for SWH and vice versa; these facts led us to follow the present methodology. We assume that an increasing trend in extreme WS may also reflect an increase of SWH on the local scale. On the other hand, as the trends studied are linear and reflect theoretical results, we also present a spatio-temporal analysis of the new records of Max SWH observed during the last decade by calculating the 
increases in differences in Max SWH observed during the last decade. This method provides a clearer appreciation of the coastal areas characterized by strong wave climate variability that may be exposed to new wave records and new disasters in the future. To carry out this sensitivity analysis, we have started by assessing the accuracy of the used wind and wave data.

\subsection{Data resources and accuracy assessment}

This study is carried out based on multi-source data of good accuracy, evaluated, and validated against the existing measures. For wave climate data, a wave hindcast database covering a 39year period was adopted and upgraded to 41 years for this study. This database was developed for an assessment of wave energy resources in Algerian coasts (Amarouche et al. 2020a) using a SWAN model calibrated specifically for the WMed Sea (Amarouche et al. 2019). This hindcast database is characterized by a high spatial resolution of $0.033^{\circ}$ and a temporal resolution of 3 hours. The physical setting adapted for the calibrated SWAN model is summarized in Table 1 and detailed in Amarouche et al. (2019).

Given the spatial sensitivity of this study, we began with a spatial assessment of the wave data used in relation to satellite observations. For this, the GO_L3_SWH_NRT_SM global ocean 13 SWH database from near real-time satellite measurements was used. This database is processed by the WAVE-TAC multi-mission altimeter data processing system and is provided by Copernicus Marine Environment Monitoring Service

(CMEMS) https://resources.marine.copernicus.eu/. This satellite altimeter observation database contains data since July 2019 from six missions of the most recent altimetry satellites, which include AltiKa, Cryosat-2, Jason-3, Sentinel-3A, Sentinel-3B and CFOSAT with a very high spatial resolution; the observations between each measurement in the same orbit is $7 \mathrm{~km}$. The observations from these satellites have been evaluated against buoy measurements by several researchers (Hithin et al. 2015; Kumar et al. 2015; Jiang et al. 2018; Yang and Zhang 2019; Ribal and Young 2019; Hauser et al. 2020) on a global scale and have proved the high quality of the SWH data provided by these satellites. In this study, the total period of satellite measurements provided by CMEMS was used, from July 2019 to the time of analysis on 31/03/2020. For a total number of 87312 observations corresponding spatially and temporally to the data simulated by the SWAN model over the entire WMed Sea. First, we started with a static error analysis of the used satellite measurements compared to the wave measurements of 24 buoys (Table 2) mooring in the WMed Sea (Fig. 1). These wave buoy data were provided by CMEMS and managed and archived by four different organizations, including Meteo France, Puertos del Estado, Centre d'Archivage National de Données de Houle In-Situ 
(CANDHIS), and Coastal Ocean Observing System in the Balearic Islands (SOCIB). These buoys have also been used to evaluate wave data over the same period to support the results of the spatial assessment with respect to the satellite data. They were also used for the evaluation of the retrospective projections of Max SWH records over the last decade.

Concerning the wind data used for forcing the wave modeling and also for trend analysis, we used CFSR reanalysis data developed and analyzed by the National Centers for Environmental Prediction (NCEP) and provided by the web services https://rda.ucar.edu/. CFSR data is characterized by a very high temporal resolution of 1 hour and covers more than 41 years, distributed in two databases. The first database is CFSR v1 (Saha et al. 2010), which covers the period from 1979 to 2010 , with a spatial resolution of $0.3125^{\circ}$ and the second database is CFSR v2 (Saha et al. 2014), which covers the period from 2010 to the present, with a spatial resolution of $0.204^{\circ}$. The choice of CFSR wind data was based on two main criteria (Amarouche et al. 2020a). Firstly, the high temporal resolution of $1 \mathrm{~h}$, which allows a better estimation of storm peaks (Tiberi-Wadier et al. 2016; Akpinar and Ponce de León 2016; Çakmak et al. 2019). Secondly, according to several studies (Stopa and Cheung 2014; Van Vledder and Akpınar 2015; Campos and Guedes Soares 2016, 2017; Carvalho 2019) this database has very good accuracy with a slight overestimation of WS, unlike other wind sources such as ERA-Interim reanalysis of the European Centre for Medium-Range Weather Forecasts ECMWF (Dee et al. 2011). According to Rusu et al. (2017) and Van Vledder and Akpınar (2015), predictions of SWH during storms using the SWAN model are often underestimated using ECMWF winds as the model forcing source. For a risk assessment study and in order to ensure sustainable development of marine activities, we consider that a slight overestimation of WS and SWH is more recommended than a slight underestimation, as the error statistics of both the WS and the SWH are taken into account in the discussion of the results. For the evaluation of the CFSR Wind in the WMed Sea, the WS measurement of two offshore meteorological stations was used (Nice and Lion buoys) to perform an errors analysis during the same period considered for the wave hindcast evaluation.

\subsection{Trend analysis method}

Currently, the remarkable climate changes that the globe has observed in recent decades (Stott et al. 2010; Romera et al. 2017; Cramer et al. 2018), with the increase in SWH and WS (Dobrynin et al. 2012; Young and Ribal 2019a; Meucci et al. 2020), an increase in storm intensity (Sobel and Tippett 2018; Kossin et al. 2020; Emanuel 2020) and storm surges (Cid et al. 2016; Adam et al. 2020), leading to increased impacts of coastal storms (Johnson et al. 2015; 
Hoshino et al. 2016; Amarouche et al. 2020b) have led the scientific community to focus on trends in these changes that may be responsible for many socio-economic damages, mainly in some vulnerable regions. Nevertheless, the non-linearity of climate variations makes the estimation of its evolution very difficult and requires continuous monitoring. Currently, the most recommended and used methods by the scientific community in the study of climate trends and their significance are the Theil-Sen estimator (Sen 1968) and the Mann Kendall test (Mann 1945; Kendall 1975). The Theil-Sen estimator is a slope estimation method based on Kendall's rank correlation (Sen 1968), initiated by Theil, (1950) and revised by Sen (1968), considering the asymptotic properties of the estimators. According to Sen (1968), this method was based on weaker assumptions and did not require that the analyzed $n$ constant values be distinct. This method, compared to the least square's estimator, is not sensitive to the non-normality. Since the waves do not generally follow a normal distribution but often Weibull distribution or Pareto distribution, the Theil-Sen may be considered more appropriate.

In the Theil-Sen slope estimate method, we need to calculate the slopes $a_{i j}$ between all possible combinations of pairs of points, of the total observations number $n$, using the following equation:

$a_{i j}=\frac{\left(Y_{j}-Y_{i}\right)}{\left(t_{j}-t_{i}\right)} \quad$ with $1<\mathrm{i}<\mathrm{j}<\mathrm{n}$

where $\mathrm{Y}$ is the observation data and $\mathrm{t}$ is the observation time. Then, the non-parametric TheilSen Slope is the median value of all pairs points slope $a_{i j}$. In this study, the Teil-Sen slope estimator was applied for all grid points for a period of 41 years. On annual wind and wave values and the significance of the trends was checked based on the Mann Kendall test as mentioned above.

Mann Kendall test is a non-parametric test developed by Mann (1945) and statistically illustrated in Kendall (1975). As for Theil-Sen's estimators, this non-parametric test does not require normality in the data distribution. The null hypothesis $\mathrm{H}_{0}$ of the Mann-Kendall test assumes that there is no trend over time, and the alternative hypothesis $\mathrm{H}_{1}$ assumes that there is an increasing or decreasing trend over time. For an observation number $n>40$ (the case of this study), we start by ordering chronologically the set of observations $\mathrm{Y}_{\mathrm{i}} \ldots . . \mathrm{Y}_{\mathrm{n}}$ and then calculate the possible $n(n-1) / 2$ differences $Y_{j}-Y_{i}$ where the $i$-values indicate the order of the years of observation; $\mathrm{i}=1$ .n- 1 , and $j=i+1$ n. The signs of the differences $Y_{j}-Y_{i}$ are used to calculate The Mann-Kendall test statistic S using the following formula 
195 where $\operatorname{sgn}\left(\mathrm{Y}_{\mathrm{j}}-\mathrm{Y}_{\mathrm{i}}\right)$ is an indicator function defined as

$196 \operatorname{sgn}\left(Y_{j}-Y_{i}\right)=1$ if $Y_{j}-Y_{i}>0$

197

$\operatorname{sgn}\left(Y_{j}-Y_{i}\right)=0$ if $Y_{j}-Y_{i}=0$

$\operatorname{sgn}\left(Y_{j}-Y_{i}\right)=-1 \quad$ if $\quad Y_{j}-Y_{i}<0$

as $\mathrm{n}>40$; the normal approximation test is used, by computing standardized S statistic denoted by $\mathrm{z}$ as follows (Rani and Sreekesh 2018).

$201 \quad Z=\left\{\begin{array}{cc}\frac{S-1}{\sqrt{\operatorname{Var}(S)}} & \text { if } S>0 \\ 0 & \text { if } S=0 \\ \frac{S+1}{\sqrt{\operatorname{Var}(S)}} & \text { if } S<0\end{array}\right.$

202 and $\operatorname{Var}(\mathrm{S})$ is computed according to the following formula

$\operatorname{Var}(S)=\frac{1}{18}\left[n(n-1)(2 n+5)-\sum_{i=1}^{m} t_{i}\left(t_{i}-1\right)\left(2 t_{i}+5\right)\right]$

204

205

206

207

208

209

210

211

212

213

214

215

216

217

where $m$ is the number of tied groups; considered as the number of tied values in the time series, it may reduce the validity of the normal approximation (Salmi et al. 2002), and $t_{i}$ is the number of data values in the $\mathrm{p}^{\text {th }}$ group up to observation $\mathrm{i}$.

To test the null hypothesis $\left(\mathrm{H}_{0}\right)$, the test statistic $\mathrm{z}$ absolute value is compared to $\mathrm{z}_{(1-\alpha / 2)}$, obtained from the standard normal table for different significance levels $\alpha$ of $0.01,0.05,0.1$, and 0.2; considered in order to observe the spatial trend of the confidence level. If $|z|>z_{(1-\alpha / 2)}$, $\mathrm{H}_{0}$ is rejected and we conclude that there is a significant trend for a confidence level of 1- $\alpha$, and depending on the $\mathrm{z}$ value sign, the trend direction is defined as increasing if $\mathrm{z}>0$ or decreasing if $\mathrm{z}<0$.

\subsection{Assessment method of wave records}

For the determination of new SWH records observed between 2010 and 2020, a simple approach was followed. This approach consists of four steps. First, the annual Max of SWH $\left(\max _{t}(S W H)\right)$ observed during the period 1979 to 2020, have been determined spatially for each point on the grid; e.g., $\max _{1979-1990}(S W H)$ is the Max value of SWH observed during the 
period 1979 to 1990. Secondly, the new increases or decreases Dif(t) of the Max SWH observed each year were calculated as follows:

$\operatorname{Dif}(t)=\left\{\begin{array}{cl}\max _{1979}(S W H) & \text { for } t=1979 \\ \max _{t}(S W H)-\max _{t-1}(S W H) & \text { for } 1979<t<2021\end{array}\right.$

Thirdly, by a simple analysis based on a single criterion defined as the sign of the value Dif $(t)$, the new records observed annually between 2010 and $2020 \mathrm{NR}(\mathrm{t})$; for each point of the grid, was defined by one value according to the following equation.

$N R(t)= \begin{cases}1 & \text { if } \quad \operatorname{Dif}(t)>0 \\ 0 & \text { if } \operatorname{Dif}(t) \leq 0\end{cases}$

In the end, the new NR (t) records as well as new increases Dif $(2010-2020)$ in the Max SWH recorded during the period 2010-2020 were mapped.

$$
\operatorname{Dif}(2010-2020)=\max _{1979-2020}(S W H)-\max _{1979-2010}(S W H)
$$

\section{Results and discussion}

\subsection{Data accuracy}

The critical aspect of this study consists in the relevance of the obtained results for the assessment of wave storm hazards and the spatial location of the most sensitive areas to wave climate variabilities. The accuracy of the data used in this study is critical to ensure a reliable analysis of the current situation. Therefore, It is necessary to present a spatial analysis of the error statistics concerning the used wind and wave data. For the spatial analysis of the wave hindcast accuracy, the satellite observation data were used in this study. Before determining the accuracy of model data against satellite data, the accuracy of satellite data against buoy data was tested. The plot on the left side of Fig. 2 shows the observation points obtained from six different satellites (AltiKa, CryoSat2, CFOSat, Jason-3, Sentinel-3a, and Sentinel-3b) and shows the locations of the buoy data where the performance of the satellite data is examined. In the plot to the right of the same figure (Fig.2), a scatter diagram of satellite data paired with measurements of 24 buoys (Fig.1) is presented. The collocation in this process has been done by considering a Max distance between buoy and satellite observation of $0.1^{\circ}$. As can be seen from this figure, the satellite data offers a very high correlation $(\mathrm{R}=0.974)$ and low error $(\mathrm{HH}=0.157$ and bias $=-0.13 \mathrm{~m})$ to the buoy data, where $\mathrm{HH}$ is referring to Hanna and Heinold, (1985) index. The accuracy of the model hindcast data could be evaluated spatially against the 
satellite data whose accuracy was proven in this direction. For the spatial analysis of the wave hindcast accuracy, we based mainly on two parameters, the correlation coefficient $(R)$ and the HH index of Hanna and Heinold (1985), which was recommended by Mentaschi et al. (2013). Mentaschi et al. (2013) demonstrated that the root means square error (RMSE) and the scatter index (SI) may not be fully able to identify the best performance of wave models and are not suitable for assessing the accuracy of wind wave models. The spatial distribution of the error indicators $\mathrm{HH}$ index and the correlation coefficient $\mathrm{R}$ obtained by comparing the results of the SWAN model with satellite measurements between July 2019 and March 2020 are presented in Fig. 3. The colocation of the hindcast data against the satellite data has been done by considering for each satellite measurement the nearest point of the simulation grid; having a hindcast data with a spatial resolution of $0.033^{\circ}$, the Max spatial error of collocations is therefore $0.0165^{\circ}$, thus, on the temporal scale only the observations which correspond precisely to the simulation time are considered. As can be seen from such results, there is a high correlation coefficient $(>0.9)$ between hindcast data and satellite data in almost all of the WMed, except in some coastal regions where the correlation coefficient can be reduced to 0.8 , which is a reasonable correlation as well. According to the HH index maps (Fig.3), a Max of 0.30 are observed in open seas, while higher $\mathrm{HH}$ index occurs around 0.40 in a small, limited part of the coastal areas. However, it can be affirmed that these error results reflect a very good performance of the wave hindcast simulation used during the present study, in almost the whole WMed Sea.

For the local evaluation of the wind and the wave hindcast accuracy with respect to buoy measurements, several parameters were considered in addition to the $\mathrm{HH}$ index and the correlation coefficient R. The formulas used to calculate the statistical error indicators are presented in Appendix A. The error analysis results for SWH are summarized in Table 3 for 24 buoys, and those of the WS are summarized in Table 4. These results clearly show the accuracy of the SWAN model used in the West Mediterranean sub-basins. In the Balearic basin, the error analysis results obtained with respect to the measurements of buoys B5, B6, B7, B8, and B9 (Fig.1 ) and presented in Table 3 shows that the correlation coefficient exceeds 0.92 with a mean HH index, a mean RMSE, a mean absolute bias and a mean index of agreement (d) of 0.26, $0.28 \mathrm{~m}, 0.09 \mathrm{~m}$ and 0.95 successively; the index of agreement (d) introduced by Willmott, (1982) indicates that the simulated values have better agreement with the measurements by approaching a value of 1 . For the Algerian basin, the average results obtained with respect to buoys B16 and B4 are $0.945,0.23,0.36 \mathrm{~m}, 0.13 \mathrm{~m}$, and 0.96 for the correlation coefficient $\mathrm{R}$, the 
HH index, the RMSE, the bias, and the index of agreement (d) successively. Concerning the results obtained in the Gulf of Lion regarding eight wave buoys (B11, B12, B13, B14, B15, B17, B18, and B19), we notice that the correlation coefficient in this area is also considerable with an average that exceeds 0.94 . Thus the average of the HH index, the RMSE, the bias, and the index of agreement (d) are successively $0.27,0.33 \mathrm{~m},-0.11 \mathrm{~m}$, and 0.95 . In the Tyrrhenian basin, the evaluation of SWAN model results compared to the measurement in buoy B24 also shows good accuracy of the simulated data; the correlation coefficient was 0.93 , the $\mathrm{HH}$ index 0.25, the $\mathrm{d}$ index 0.96 , and the RMSE and bias were 0.22 and 0.04. Also, a high average correlation coefficient of 0.93 is found compared to buoys B20, B21, B22, and B23 located in the Ligurian basin north of the Tyrrhenian basin, where the mean HH index and $\mathrm{d}$ index are successively 0.28 and 0.94 , and the mean RMSE and bias are successively 0.40 and 0.13 . Finally, for the Alboran basin, the average correlation coefficient obtained for buoys B1, B2, and B3 is 0.90, and for the averages of HH index, RMSE, bias, and agreement index (d), the results are $0.32,0.27 \mathrm{~m}, 0.1 \mathrm{~m}$ and 0.93 respectively. In general, the average correlation coefficient for all 24 buoys exceeds 0.93 , which reflects a very high accuracy of the SWAN model used for the development of the hindcast database and reflects the high reliability of the trend wave analysis results presented in this study. Further, the scatter plots illustrated in Fig. (A.1) allows us to appreciate the performance of the model at the 24 buoys and show in the set high linearity and low dispersion of the estimated data compared to the measured data.

For the local evaluation of the CFSR hindcast wind data, the error analysis results obtained in relation to the measurement of the two offshore wind and wave measuring buoys B17 and B22 observed from $01 / 07 / 2019$ to $31 / 03 / 2020$, that corresponds to the same period considered for the evaluation of the wave data accuracy compared to the satellite observation and also compared to the wave buoy measurements. The results of this analysis, summarized in Table 4, show that CFSR wind speeds have good accuracy. The correlation coefficients obtained with respect to the measurements are 0.91 and 0.87 for B17 and B22 successively with an average bias and RMSE of $0.59 \mathrm{~m} / \mathrm{s}$ and $2.14 \mathrm{~m} / \mathrm{s}$, respectively, showing a slight overestimation of the WS, as well as the average HH index and agreement index (d) are 0.29 and 0.94 successively. These results confirm that the CFSR WS has a high agreement with the measurements. The scatter plots presented in Figure 4 shows as well a linear distribution and a good correlation between the CFSR data and the measured data with low dispersion and a slight overestimation of the offshore WS at Lion buoys B17 and an acceptable dispersion at Nice Buoy B22; located in a complex morphological area closer to the coasts between Corsica and Monaco. 


\subsection{Wind and Wave Trends}

313 The peculiarity of the temporal trend results of wave climate obtained and discussed in this study is that the results are presented and compared simultaneously with wind trends and new wave records, which together may constitute a supporting indicator for a better assessment of wave climate variations. Thus, on the temporal view, different trends have been analyzed for different scales, and the comparison of the results obtained in this study with the previous studies carried out in the Mediterranean Sea allowed us to observe the spatial variations of wave climate trends depending on the period considered and how new extreme events can influence the results of the trend analyses.

321

First, we start with the annual trends in mean WS (WS_Mean) and mean SWH (SWH_Mean), observed over 41 years and presented in Fig 5. According to these results, a significant increasing trend in SWH is clearly observed over almost the whole WMed Sea, with a confidence level of 95\%. In the North of the Tyrrhenian Basin, the estimated slopes indicate an increase of 0.2 to $0.6 \mathrm{~cm} /$ year, in the western part of the Gulf of Lyon, a growth of 0.4 to 0.8 $\mathrm{cm} /$ year was observed, and also in the Balearic Basin and almost all the Algerian Basin with an increase of 0.4 to $0.8 \mathrm{~cm} /$ year. Concerning the annual WS_Mean trends, a spatial correlation is observed between the coastal areas characterized by a significant trend of WS_Mean and SWH_Mean, except for Almeria and Malaga coasts, where a significant increase in WS is observed against a non-significant decreasing trend of SWH. These results can be related to the dominant wind direction, mainly from SW in Almeria and followed by W and NE winds, based on Almeria Metrological Station data from Puertos del Estado website (Puertos.es). Thus, these results can be due to the small fetch distance in this area, which does not allow a local wind sea generation by the local wind. The variation of swell and wind sea contributions in the total wave height may explain the differences in trends between SWH and WS observed in some areas. The gaps in information regarding the variability in wave spectral climate in the Mediterranean Sea impede a full explanation of the present finding. A detailed spectral wave climate analysis in the WMed Sea is highly required to support the current discussion.

According to Young et al. (2011) results, an increasing trend of the WS_Mean was estimated between 1991 and 2008 in the entire WMed Sea. Thus, Young et al. (2011) analyzed the trends of the SWH-mean between 1985-2008 and showed a decreasing trend in SWH_Mean in the WMed Sea. These trend analyses have been upgraded by Young and Ribal (2019a) by analyzing SWH_Mean trends for the periods from 1985 to 2018. The obtained result shows this time an increasing trend of annual SWH_Mean over the whole WMed Sea. This radical change in trends 
may reflect an acceleration of the rising SWH_Mean in the WMed Sea. For the WS_Mean trends, we noted that the areas characterized by a significant increasing trend in WS_Mean between 1979 and 2014, according to Soukissian et al. (2018) results, are the eastern part of the Algerian basin and also the east part of Corsica and Sardinia. In contrast, the Northeast European coast was characterized by an increasing but no significant trend. By comparing these results with those obtained during this study, the acceleration in WS increases on the north-western coasts of the Mediterranean Sea may be at the origin of the significant trend observed in this area. However, for a consistent evaluation, we consider it essential in such a study to refer back to the spatial performance of the Hindcast database based on different wave buoys. E.g., it is observed that the wind hindcast data shows a higher positive bias in the Lion buoy compared to the Nice buoy (Table.3). Wind and wave models often show a slight positive or negative bias changing depending on the buoy location and increasing or decreasing proportionally with WS and SWH. Consideration of error statistics of the used models allows reliable comparisons between the finding reported in different studies.

Comparing the SWH_Mean trend results with the recent result obtained by De Leo et al. (2020), who analyses 40 years wave hindcast from 1979 to 2018, we notice a considerable difference. The areas characterized by a significant increasing trend of SWH_Mean shown during this study over the WMed Sea are much larger than the areas estimated by De Leo et al. (2020). However, the results are in line with those observed by Yuchun and Leo (2020), who estimate SWH and WS trend between 1993 and 2015 based on satellite observations and estimate a significant increase in both WS and SWH in almost the whole WMed Sea, and in all west European coasts. Moreover, as mentioned before, the annual trend in SWH_Mean between 1985 and 2018 estimated and mapped in Young and Ribal (2019b) based on satellite observation show a significant increasing trend in almost all WMed Sea, which supports our results. The annual trend in SWH and WS means was also evaluated by Meucci et al. (2020), using a century-long wind and wave reanalysis covering the 1901 to 2010 period. The results obtained by Meucci et al. (2020) show a significant increasing trend in the SWH and WS means in the WMed Sea for both ERA-20C (Poli et al. 2016) and CERA-20C (Laloyaux et al. 2018) reanalysis. The differences noticed in the present study results compared to the results obtained by De Leo et al. (2020) can be explained by the used model performances. In the present study, the wave model in several locations as presented in (fig. A1), tends to overestimate the wave heights. The more the SWH is high, the more the bias increases. Consequently, if the frequency of extreme events increases, the bias may also increase, leading to a probable overestimation of 
the slopes and their significance. However, as the biases are mainly positive, these consequences do not exclude the possibility of drawing any conclusions regarding the estimated increasing trends in buoy location with a positive bias, but an overestimation is to be expected. On the other hand, by observing the statistical errors of wave hindcast data used by De Leo et al. (2020), developed and evaluated by Mentaschi et al. (2015), we notice from Mentaschi et al. (2015) results that the normalized bias of the SWH is negative for wave heights above 1.7 $\mathrm{m}$ and the more the negative SWH increases, the more the normalized bias decreases. Consequently, suppose the frequency of annual extreme wave events increases in the disfavor of calm sea states; in that case, we may expect that the negative bias will decrease more and more, and the annual averages may be further underestimated. This statistical phenomenon may as well explain why the areas marked by an increasing trend in SWH-max and SWH-p90 (Percentile 90 of SWH) are more extensive compared to the areas marked by an increasing trend in the annual SWH-mean from the results of De Leo et al. (2020).

On a seasonal scale, the trends of the annual averages of the SWH and WS (Fig. 6) show that some areas characterized by an increasing trend on the annual scale are characterized by a decreasing trend on the seasonal scale and vice versa. During the summer season, only the coast of the Gulf of Lyon shows a significant increasing trend, and in most of the East and West coasts, a decreasing trend of SWH and WS is observed. During the spring period, it is noted that the areas characterized by an increasing trend of SWH and WS are almost the same areas marked on the annual scale with lower confidence levels except for the Alboran Basin, where the area characterized by an increasing trend of SWH on the annual scale was considerably expanded. Thus, confidence levels have also increased to 99\%. In the Alboran Basin, the coastal areas considered to have a no significant decreasing trend on the annual scale are characterized by a significant increasing trend. These findings suggest that the annual SWH_Mean trends may be insufficient to describe the risks associated with climate variations in specific regions and during a particular season. According to Casas-Prat and Sierra (2013) the wave climate patterns during the summer season are different from winter. The results of wind and wave climate projection obtained by Casas-Prat and Sierra (2013) show a significant increase in future climate projections (2071-2100) of wind sea, swell, and WS in the Gulf of Lion; as a result of five different wave climate models. Thus, in the Balearic sea, several models projected a future increase in these climate parameters (Casas-Prat and Sierra 2013). For the Autumn season, we observe a significant increasing trend in the West part of Lyon gulf and in the East part of Corsica and Sardinia, where the Theil-Sen slope indicates a growth of 0.4 to $0.8 \mathrm{~cm}$. 
year-1. In those areas, an increasing trend is also observed in winter but with a higher slope $(0.6$ to $1 \mathrm{~cm}$.year-1) and a lower confidence level. Significant increasing trends have also been observed for all four seasons in these two areas. On the other hand, it is also remarkable that the Tarragona coast, which was heavily exposed to the extreme waves during the Gloria storm, was not considered as an area with a significant increasing trend in SWH-mean, and no significant future change in SWH median was estimated during the winter season by CasasPrat and Sierra (2011). in this area, the trend in SWH and WS means may not reflect a trend in extreme events, and evaluations of extreme events trends and variability may be necessary.

Regarding the trends of the annual SWH_Max and WS_Max (Fig. 7), the results show several remarkable differences compared to the average trend results with several similarities. It is notable that the Monaco coasts experience a very significant increasing trend of SWH_Max and WS_Max with a confidence level of $99 \%$ and a slope of 2 to $3 \mathrm{~cm}$.year ${ }^{-1}$ of SWH_Max and 0.04 to 0.012 m.s-1 .year ${ }^{-1}$ of WS_Max. Precisely this coastal zone has no significant trend of SWH, and WS means on both annual (Fig. 7) and seasonal (Fig. 8) scales. The increase observed in the WS-max and SWH_Max in this area can be related to the cyclone-track regimes in this zone; Monaco coasts and all Golf of Genoa were characterized as the central region of cyclogenesis in the Mediterranean sea by Nissen et al. (2010). Thus, a trend analysis of cyclonetrack and wind track density between 1957 and 2002 developed by Nissen et al. (2010) shown a significant decreasing trend in cyclone-track number in the WMed and a significant increase in the wind track density; mainly in Europe and in Genoa and Lion gulfs. Variation in cyclogenesis regime in Genoa gulf may explain the difference in the trend of WS_Mean and WS_Max

In the Algerian basin, results show that a significant area characterized by a significant increasing trend of SWH-mean and WS_Mean had recorded a non-significant trend for SWH_Max and WS_Max with a decreasing trend in the east of the Algerian basin. The observed differences in the significance confidence level of the annual SWH_Max trends between the Spanish and French coast and the Algerian and Tunisian coast can be explained by a variation in the dominated direction of the extreme wind in these areas or by variation in cyclogenesis regime in these two zones (Nissen et al., 2010). The south-eastern coast of the Algerian basin is dominated by waves from the NNW, NW, and Western sectors (Amarouche et al. 2020a), which can be associated with Tramontane, Mistral, and Ponente winds. Thus, According to Soukissian et al. (2017) results, during the winter season, the average wind direction in the European coast is from the NW sector. However, the average wind direction 
during the same season in the Algerian coasts is from the Western sector in the Eastern coast and from the WNW sector in the Western coasts (Soukissian et al., 2017). The no significant trend of SWH_Max and WS_Max, in the Algerian and Tunisian coast can be related to higher extreme events that occurred in earlier periods in these areas from western sectors. The North and South part of the WMed Sea may be affected by different climate patterns. Lionello and Galati (2008) relate several climate patterns to the variations in the wave climate of the WMed Sea; the East Atlantic Pattern (EA), the Scandinavian Pattern (SCA), the North Atlantic Oscillation (NAO), the East Atlantic/West Russia Pattern (EA/WR), and even the East Pacific/North Pacific Pattern, (EP/NP). A detailed directional spectral analysis of wind-wave climate linked to different climate patterns may provide better understanding.

On a seasonal scale (Fig. 8), a significant increasing trend in SWH-max can be observed off the central coast of Algeria during the spring season and the Autumn season, with confidence levels of $95 \%$ to $99 \%$ and a slope that varies from 2 to $4 \mathrm{~cm}$. year ${ }^{-1}$ for the SWH_Max and from 0.04 to 0.08 m.s-1 for the WS_Max. In this area off the central coast of Algeria, an increase in storm intensity and the annual number of wave storm events has been reported in Amarouche et al. (2020b). Another interesting observation is that a significant part of the South-East Tyrrhenian basin shows a significant decreasing trend with a confidence level of $99 \%$ in the winter season and a significant increasing trend in the spring season, reflecting a seasonality effect in this area. Also, during the winter season (the Gloria storm Season), no significant increasing trend was recorded in the Catalan coast, where records of Max SWH were measured by buoys during the Gloria storm. On the other hand, the trends of WS_Max show clearly a very significant increasing trend with a confidence level of $99 \%$. It is reminded that the wind and wave climates of the year 2020 were not considered during the trends analysis.

Thus, in order to observe the effect of storm Gloria on wave trend results, we developed a trend analysis of mean and Max SWH during the winter season based on the same method by considering the winter of 2020. It is to be noted that the months considered for a winter of year $t$ are December of the year $t-1$ and January and February of the year $t$ with $t>1979$, while for the winter of 1979, only January and February were considered. The results of this analysis (Fig. 9) clearly show that the consideration of the wave climates of winter 2020 has considerably increased the Theil-Slope estimated for the Max SWH in the western part of Gulf de Lyon and in the Balearic Sea, estimated based on 41 years of wave climate. This increase is about $1 \mathrm{~cm}$ and represents a 30\% increase in almost all of this area. For the trend's significance, we also observe an increase in the confidence level in the central part of the Balearic basin at 
$90 \%$ and in the west of the Gulf of Lyon at $99 \%$. Based on these results, we can observe that the climatic data of a year can considerably influence the results of the wave trends. Therefore, we recommend annual continuous monitoring for this kind of study. This estimated change in trends is also remarkable when comparing our results with those of De Leo et al. (2020) based on the annual wave climate between 1979 and 2018, where a difference of almost $1 \mathrm{~cm}$ more in the slope is also observed in the Catalan coasts and west of the Gulf of Lyon by considering the year 2019 in the trend analysis. During the summer season, significant increasing trends of WS_Max were also estimated near Gibraltar Channel (Fig. 8), while an increasing trend of SWH_Max is estimated along the South-Western coast of West orientation. Based on these results, we can estimate that the increasing trend of WS_Max can be from the West sector, which can be linked to the Vendavel winds originating from the Atlantic Ocean and/or linked to the Atlantic climate Patterns (Lionello and Galati 2008).

In general, by comparing the areas characterized by a significant increasing trend of SWH_Max for all four seasons compared to areas observed on the annual SWH_Max trend, we observed that a significant area of the WMed Sea characterized by a significant increasing trend on a seasonal scale had not been considered as such in the annual scale trend results, including the Algiers coast where an increase of storm events was reported in (Amarouche et al. 2020b) as only a Max value SWH was considered each year during the annual trend analysis of SWH max. These annual values can be obtained in different seasons and different months during the years and cannot reflect increases or decreases in storm events and intensities. As well, the annual change in SWH max may not reflect a change in SWH_mean. For a better's consideration of the annual trends in SWH-max by considering the seasonality effects, we developed a trend analysis of the annual average of monthly SWH_Max. The results of this analysis (Fig. 10) shown an increasing trend of SWH_Max over almost the whole WMed Sea. With a confidence level above $95 \%$ and a Theil-slope of 2 to $4 \mathrm{~cm}_{\text {.year }}{ }^{-1}$ in the west of Gulf of Lyon, 2 to $3 \mathrm{~cm}$.year $^{-1}$ in the West of Corsica, and 1 to $2 \mathrm{~cm}$ off Tarragona, in the East of Corsica, in the East of Sardinia and the Algerian basin. These results may reflect an increase in the intensity of extreme wave events in several zones in the WMed sea. The hypothesis of a causal link between these observed variations and the global acceleration of climate change over the last two decades reported by Cramer et al. (2018) can be a perspective for future studies. According to Cramer et al. (2018), the global acceleration in climate change can point to significant risks during the following decades. In terms of future projections of SWH in the West Mediterranean, results obtained by Lobeto et al. (2021) show a probable increase in the 
99th percentile bias of SWH under the Representative Concentration Pathway (RCP8.5) scenario. Thus, regional study related to future wave climate change (Bricheno and Wolf 2018) reported as well a probable significant increase of the winter and summer SWH-max in large part of the WMed Sea, for both RCP 8.5 and RCP 4,5 emissions scenarios, precisely during the end of the current century (2070-2099). However, in the same study and several other studies (Semedo et al. 2013; Perez et al. 2015; De Leo et al. 2021), a decrease in SWH mean was projected at the end of the present century. The result of the historical trend presenting during this study may warn of a likely change in the near future, but uncertainties may arise in terms of a long-term projection of current trends. The use of climate models with continuous updating and reanalysis may be recommended for future projections related to climate changes. Thus, further focused studies can be necessary to evaluate the links between the present variations in wind-wave climate and the global warming phenomenon.

\subsection{Wave records}

The results of the wave record assessment summarized in Fig. 11 show the different areas affected by waves records since 2010 with the total increases observed during this period compared to the 42 years of analyzed wave climate. Moreover, the results presented in the maps are supported and verified against the instituted measures of eight wave-buoys shown in Fig. 11. Comparing the successive records of annual SWH max estimated between 2010 and 2020 based on the hindcast data against the records achieved by measuring buoys during the given period presented with a red dot on the time series plots (Fig. 11); we noted a strong similarity between the estimated results and the observation. This simple comparison, based on buoy measurements, clearly shows the validity of the results estimated for the wave records spatially and temporally. The wave records map, Fig. 11, show clearly that about more than $50 \%$ of the West Mediterranean coasts experienced a record of SWH since 2013 over a period of 42 years. Moreover, in the Catalan coast, the Monaco coast, and Sardinia's East coast, three successive records have been registered during this period. Practically, in most areas that have recorded this record-breaking, the results of trend analysis of Max SWH show significant increasing trends. However, the estimated Theil-Sen linear slopes are in the range of 1 to $4 \mathrm{~cm}$. year ${ }^{-1}$ in several areas that have experienced increases in Max SWH exceeding $50 \mathrm{~cm}$ since 2013. In Catalan coasts, the estimated difference exceeded $250 \mathrm{~cm}$ off Tarragona as a result of the Gloria storm. This considerable and inestimable difference has caused enormous damage to the Spanish coast (Amores et al. 2020), and the intensity of this record-breaking storm was illustrated in several amateur videos that record this tragic event, e.g., the following YouTube 
video: https://www.youtube.com/watch?v=DCZ6g9boM-Q. Referring to the same map (Fig. 11), in the Eastern coast of Sardinia, the coasts of Genoa, Monaco, Almeria, and Oran, a difference in SWH of about 25 to $100 \mathrm{~cm}$ has also been estimated since 2013. As we have already noted, the Tarragona coast affected by SWH records in 2020 has experienced a nonsignificant trend of Max SWH and a significant trend with a confidence level of $99 \%$ for the WS max. Besides, the southern coast of Sardinia, which recorded two successive SWH records in 2013 and 2017, has also been considered as an area with a non-significant trend of SWH max, but for the WS _Max, the trend has been significant for the spring season. The significant increasing trend in WS max may likely reflect a possibility of increasing SWH in this area. Based on these results, we strongly recommend consideration of WS trends and variability during coastal hazard studies and for sustainable planning and design of coastal protection structures.

In the Algerian coast, Unlike the Alboran basin and the North European coasts, only three SWH records have been estimated in limited areas next to the Algiers coast in 2014, off Algiers in 2015, and between Algiers and Annaba (Bejaia coast) in 2017. Both record-breaking of 2014 and 2015, was characterized successively as extreme and catastrophic storms and were responsible for several damages reported in (Amarouche et al. 2020b). On the other hand, the limited area and number of SWH records in the Algerian basin may be due to severe wave storm events, in terms of SWH, that occurred before 2010, such as the catastrophic storm events of 2001 and 2007 off Algiers (Amarouche et al. 2020b).

Primarily, it is required to pay special attention to the Western zone of the Gulf of Lyon and to the Eastern part of Sardinia, which has recorded significant increasing trends for average and Max SWH and WS on an annual scale and during the four seasons. This area constitutes a real hot spot with a stable and continuous increasing trend. Moreover, the consecutive extreme records of SWH observed recently in the Mediterranean Sea can be a subject of a further regional study on the causes and causality of these extreme wave events and their connection with global warming, noting that the Mediterranean area is considered as a climate change hotspot by Tuel and Eltahir, (2020).

\section{Conclusions}

In the present study, the changes in wave climates observed during more than 41 years in the WMed Sea were evaluated by analyzing the trends of mean and Max SWH and WS and by locating the area that experienced new records of extreme SWH during the last decade. This 
study is motivated by the outstanding storms observed in 2018, and 2020 (storm Adrian and storm Gloria), which caused enormous damage in the European coasts, and also by the increase in the intensity and number of storms on the coasts of Algiers (Amarouche et al. 2020b), in addition to the influence of global climate change on the Mediterranean Sea pointed out by several researchers (Adloff et al. 2015).

Wind and wave trends are analyzed simultaneously for a 41-year period on a seasonal and annual scale using the Theil-Sen method for slope estimation and the Mann Kendall method to test the significance of the trends at different confidence levels. Thus, a simple spatio-temporal analysis method was adopted for the determination of new wave records, and the results were compared to wave buoy measurements, and also new increases observed over the last ten years were estimated and mapped.

To conduct this study, a wind and wave hindcast database was used after a spatial assessment based on observations of the most recent altimetry satellites and measurements of several buoys. The statistical error analysis carried out for the evaluation of data accuracy shows that wave hindcasts have high accuracy with a correlation coefficient exceeding 0.9 and an HH index lower than 0.30 in almost the whole Mediterranean Sea. Thus, for the CFSR wind data, high accuracy was observed by comparing the CFSR data against observations from two offshore wind buoys (Lyon and Nice buoys). The correlation coefficient (R) at Lyon and Nice buoys were 0.91 and 0.87 , respectively, and the $\mathrm{HH}$ index was 0.26 and 0.32 , respectively. Thus, the high values of the correlation coefficient obtained for the wind and wave hindcasts reflect accuracy in the trend analysis results.

Based on the spatial analysis results of WS and SWH trends and on the identified SWH records, several relevant conclusions can be reached. Mainly, most of the WMed Sea experience a significant increasing trend in SWH and mean annual WS. Compared to the seasonal means, the trends are also positive for winter, spring and autumn, but for the summer season, the trend is significantly negative in the East and West coasts of the basin. Thus, an apparent interseasonal variation in trends was observed; several areas characterized by a significant increasing trend in the spring are not characterized as such in the other seasons.

For the changes in maximum wave heights, the areas characterized by significant trends of annual SWH-max and annual WS-max (Fig. 7) are smaller than those defined for annual SWHmean and annual WS_Mean (Fig. 5). Nevertheless, trend results of the annual average of monthly SWH_Max show larger areas with significant increasing trends, mainly in European 
regions (Fig. 10). These findings highlight an inter-seasonal variability of SWH_Max and WS_Max trends and underline the importance of multi-temporal scales analysis to assess wind and wave trends.

A significant spatial matching is observed between the results of the wind and wave trends. Nearly all coastal areas characterized by significant SWH trends are also characterized by significant WS trends. However, conversely, several coastal areas characterized by significant trends in Max WS and which experienced successive wave records since 2013 have not recorded significant trends in SWH_Max. It is assumed that significant increasing trends of WS_Max in a given area may forewarn about a possible increase in SWH_Max and that the study of WS trends simultaneously with SWH trends can provide additional valuable guidance in the estimation of the likely risks associated to wave climate change.

The trend results obtained in this study based on 41-year wave climate, compared to the results of previous studies (Young et al. 2011; Soukissian et al. 2018; Laloyaux et al. 2018; Young and Ribal 2019a; Meucci et al. 2020; Yuchun and Leo 2020; De Leo et al. 2020), carried out over earlier periods and comparing the annual trend of mean and Max SWH in the winter period over 41 years versus the results obtained by considering the year 2020 (42 years), allowed us to observe variability in the estimated slopes in relation to the different analyzed periods; e.g., in the winter season, we estimated an increase in the slope of SWH_Max in the Gulf of Lion and the Balearic sea linked to Gloria storm event. According to de Alfonso et al. (2021), this event changed the distribution function of extreme values in the Balearic Sea and led to a considerable modification of the results of the extreme wave analysis. It is highly recommended to carry out continuous annual monitoring of wind and wave trends in the Mediterranean Sea. Since 2013, about half of the West Mediterranean coasts have registered records in wave climate, not recorded at least since 1979, and several regions have registered three successive records. This finding may support the hypothesis regarding a probable link between acceleration in wave climate change in the Mediterranean sea in the past two decades (Cramer et al. 2018) and the recent extreme wind and wave events. However, a detailed study is necessary to evaluate such a relationship.

The most affected areas by wind and wave climate variabilities, defined based on a spatial assessment of new wave records and the trend analysis results, are mainly Catalan coasts and Eastern Sardinian coasts, Geneva Coast and Monaco Coast, having recorded three successive SWH records since 2013 and also the West Coast of Golf de Lyon where a new record was reported in 2013, and a significant increasing trend with $99 \%$ confidence level was also noted 
for WS and SWH, for all seasons and with a considerable annual increase in slope estimated between 1979 to 2019 compared to that estimated by De Leo et al., (2020) between 1979 to 2018. Overall, the European coasts and some African coasts are witnessing a worrying risk related to the wind and wave climate that requires serious mobilization for the prevention of probable catastrophic wave storm events and to ensure sustainable and economic development. The variable rates of climate change make long-term investment decisions more difficult, and new infrastructure must deal with all eventual climate change scenarios (Hallegatte 2009). We consider that it is necessary for the next years to perform annual monitoring of SWH trends variation, considering that extreme wave values can considerably influence the trend significance levels and that annual monitoring can be necessary for upgrading the results of extreme wave analysis in the WMed Sea.

\section{Declarations}

\section{- Funding}

The authors did not receive support from any organization for the submitted work.

\section{- Conflicts of interest}

The authors have no conflicts of interest to declare that are relevant to the content of this article.

\section{- Availability of data and material}

The datasets generated during and/or analysed during the current study are available from the corresponding author on reasonable request.

\section{Acknowledgment}

The authors acknowledge the NCEP/UCAR Research data archive service for providing the wind forcing data of NOAA NCEP Climate Forecast System Reanalysis (CFSR) and Copernicus Marine Environment Monitoring Service (CMEMS) for providing altimeter data and wave buoy measurements. 


\section{Appendix A. Definitions of statistical error parameters}

670 Model results are evaluated using standard error statistics, which include; bias (BIAS), used for 671 the detection of systematic errors, root mean square error (RMSE) and mean absolute error 672 (MAE) used for measuring accuracy of the data, Pearson's correlation coefficient (R) which 673 estimates variance, the scatter index (SI) which measures relative errors, Normalized bias 674 (NMB) which shows the model tendency to overestimation or underestimation relative to the 675 measurements, the index of agreement (d) introduced by Willmott, (1982) which varies from 0 676 to 1 with higher index values indicating that the simulated values have better agreement with 677 the measurements, and lastly, normalized root mean square error $(\mathrm{HH})$ introduced by Hanna 678 and Heinold, (1985) and used by Kazeminezhad and Siadatmousavi, (2017) which is not biased

679 toward simulations that under-estimate the average and not sensitive to the mean observed 680 values. They are here characterized as follows:

681

$$
R=\frac{\sum_{i=1}^{N}\left(\left(P_{i}-\bar{P}\right)\left(O_{i}-\bar{O}\right)\right)}{\left[\left(\sum_{i=1}^{N}\left(P_{i}-\bar{P}\right)^{2}\right)\left(\sum_{i=1}^{N}\left(O_{i}-\bar{O}\right)^{2}\right)\right]^{1 / 2}}
$$

682

$$
R M S E=\left[\frac{1}{N} \sum_{i=1}^{N}\left(P_{i}-O_{i}\right)^{2}\right]^{1 / 2}
$$

683

$$
S I=\frac{R M S E}{\bar{O}}
$$

684

$$
\text { bias }=\bar{P}-\bar{O}
$$

685

$$
M A E=\frac{1}{N} \sum_{i=1}^{N}\left|P_{i}-O_{i}\right|
$$

686

$$
N M B=\frac{\sum_{i=1}^{N}\left(P_{i}-O_{i}\right)}{\sum_{i=1}^{N}\left(O_{i}\right)}
$$




$$
d=1-\frac{\sum_{i=1}^{N}\left(P_{i}-O_{i}\right)^{2}}{\sum_{i=1}^{N}\left(\left|P_{i}-\bar{O}\right|+\left|O_{i}-\bar{O}\right|\right)^{2}}
$$

688

$$
H H=\sqrt{\frac{\sum_{i=1}^{N}\left(P_{i}-O_{i}\right)^{2}}{\sum_{i=1}^{N}\left(P_{i} x O_{i}\right)}}
$$

689

$$
\bar{P}=\frac{1}{N} \sum_{i=1}^{N} P_{i}
$$

690

$$
\bar{O}=\frac{1}{N} \sum_{i=1}^{N} O_{i}
$$

691

692 where $\mathrm{O}_{\mathrm{i}}$ is the observed value, $\bar{O}$ is the mean value of the observed data, $\mathrm{P}_{\mathrm{i}}$ is the predicted 693 value, $\bar{P}$ is the mean value of the predicted data, and $\mathrm{N}$ is the total number of data.

694 For non-directional parameters, we also computed the linear regression lines according to the 695 statistical model

$$
y=c x
$$

696 for which the coefficients were estimated using a least squares analysis.

697

698

699

700

701

702

703

704

\section{References}

Adam RJ, Hilton MJ, Jowett T, Stephenson WJ (2020) The magnitude and frequency of storm surge in southern New Zealand. New Zeal J Mar Freshw Res 1-16. https://doi.org/10.1080/00288330.2020.1764596

Adloff F, Somot S, Sevault F, et al (2015) Mediterranean Sea response to climate change in an ensemble of twenty first century scenarios. Clim Dyn 45:2775-2802. https://doi.org/10.1007/s00382-015-2507-3

Akpinar A, Ponce de León S (2016) An assessment of the wind re-analyses in the modelling 
of an extreme sea state in the Black Sea. Dyn Atmos Ocean 73:61-75. https://doi.org/10.1016/J.DYNATMOCE.2015.12.002

Amarouche K, Akpinar A (2021) Increasing trend on stormwave intensity in thewestern mediterranean. Climate 9:1-17. https://doi.org/10.3390/cli9010011

Amarouche K, Akpınar A, Bachari NEI, et al (2019) Evaluation of a high-resolution wave hindcast model SWAN for the West Mediterranean basin. Appl Ocean Res 84:225-241. https://doi.org/10.1016/J.APOR.2019.01.014

Amarouche K, Akpinar A, Bachari NEI, Houma F (2020a) Wave energy resource assessment along the Algerian coast based on 39-year wave hindcast. Renew Energy 153:840-860. https://doi.org/10.1016/j.renene.2020.02.040

Amarouche K, Akpınar A, Çakmak RE, et al (2020b) Assessment of storm events along the Algiers coast and their potential impacts. Ocean Eng 210:107432. https://doi.org/10.1016/j.oceaneng.2020.107432

Amores A, Marcos M, Carrió DS, Gómez-Pujol L (2020) Coastal impacts of Storm Gloria (January 2020) over the north-western Mediterranean. Nat Hazards Earth Syst Sci 20:1955-1968. https://doi.org/10.5194/nhess-20-1955-2020

Booij N, Ris RC, Holthuijsen LH (1999) A third-generation wave model for coastal regions: 1. Model description and validation. J Geophys Res 104:7649-7666. https://doi.org/10.1029/98JC02622

Bricheno LM, Wolf J (2018) Future Wave Conditions of Europe, in Response to High-End Climate Change Scenarios. J Geophys Res Ocean 123:8762-8791. https://doi.org/10.1029/2018JC013866

Burden A, Smeaton C, Angus S, et al (2020) Impacts of climate change on coastal habitats, relevant to the coastal and marine environment around the UK Coastal response to sea level change View project Impacts of climate change on coastal habitats, relevant to the coastal and marine environment aro. MCCIP Sci Rev 2020:228-255. https://doi.org/10.14465/2020.arc11.chb

Çakmak RE, Akpinar A, Van Vledder GP (2019) Comparative Performance Analysis of Different Wind Fields in Southern and North-Western Coastal Areas of the Black Sea. Mediterr Mar Sci 20:427-452. https://doi.org/10.12681/mms.16060 
Campos RM, Guedes Soares C (2016) Comparison and assessment of three wave hindcasts in the North Atlantic Ocean. J Oper Oceanogr 9:26-44. https://doi.org/10.1080/1755876X.2016.1200249

Campos RM, Guedes Soares C (2017) Assessment of three wind reanalyses in the North Atlantic Ocean. J Oper Oceanogr 10:30-44. https://doi.org/10.1080/1755876X.2016.1253328

Carvalho D (2019) An assessment of NASA's GMAO MERRA-2 reanalysis surface winds. J Clim 32:8261-8281. https://doi.org/10.1175/JCLI-D-19-0199.1

Casas-Prat M, Sierra JP (2013) Projected future wave climate in the NW Mediterranean Sea. J Geophys Res Ocean 118:3548-3568. https://doi.org/10.1002/jgrc.20233

Casas-Prat M, Sierra JP (2011) Future scenario simulations of wave climate in the NW Mediterranean Sea. J. Coast. Res. 200-204

Cavaleri L, Bajo M, Barbariol F, et al (2019) The October 29, 2018 storm in Northern Italy An exceptional event and its modeling. Prog Oceanogr 178:102178. https://doi.org/10.1016/j.pocean.2019.102178

Cid A, Menéndez M, Castanedo S, et al (2016) Long-term changes in the frequency, intensity and duration of extreme storm surge events in southern Europe. Clim Dyn 46:15031516. https://doi.org/10.1007/s00382-015-2659-1

Cramer W, Guiot J, Fader M, et al (2018) Climate change and interconnected risks to sustainable development in the Mediterranean. Nat Clim Chang 8:972-980. https://doi.org/10.1038/s41558-018-0299-2

Csekits C, Troisi A (2018) Extreme weather events don't follow borders: Low Adrian caused severe damage in Western and Central Europe during the last days of October 2018

De Leo F, Besio G, Mentaschi L (2021) Trends and variability of ocean waves under RCP8.5 emission scenario in the Mediterranean Sea. Ocean Dyn 71:97-117. https://doi.org/10.1007/s10236-020-01419-8

De Leo F, De Leo A, Besio G, Briganti R (2020) Detection and quantification of trends in time series of significant wave heights: An application in the Mediterranean Sea. Ocean Eng 202:107155. https://doi.org/10.1016/j.oceaneng.2020.107155 
Dee DP, Uppala SM, Simmons AJ, et al (2011) The ERA-Interim reanalysis: configuration and performance of the data assimilation system. Q J R Meteorol Soc 137:553-597. https://doi.org/10.1002/qj.828

Dobrynin M, Murawsky J, Yang S (2012) Evolution of the global wind wave climate in CMIP5 experiments. Geophys Res Lett 39:. https://doi.org/10.1029/2012GL052843

Emanuel K (2020) Evidence that hurricanes are getting stronger. Proc Natl Acad Sci 117:202007742. https://doi.org/10.1073/pnas.2007742117

Garcia-Herrera RF, Lionello P, Ulbrich U (2014) Preface: Understanding dynamics and current developments of climate extremes in the Mediterranean region. Hazards Earth Syst Sci 14:309-316. https://doi.org/10.5194/nhess-14-309-2014

Geeson N, Brandt CJ, Thornes JB (2002) Mediterranean desertification : a mosaic of processes and responses. John Wiley \& Sons

Gulev SK (2004) Last century changes in ocean wind wave height from global visual wave data. Geophys Res Lett 31:L24302. https://doi.org/10.1029/2004GL021040

Hallegatte S (2009) Strategies to adapt to an uncertain climate change. Glob Environ Chang 19:240-247. https://doi.org/10.1016/j.gloenvcha.2008.12.003

Hanna SR, Heinold DW (1985) Development and application of a simple meHanna, S.R., Heinold, D.W., Health, A.P.I., Dept, E.A., Environmental Research \& Technology, I., 1985. Development and application of a simple method for evaluating air quality models, API publication. American Pe. American Petroleum Institute

Hauser D, Tourain C, Hermozo L, et al (2020) New Observations From the SWIM Radar OnBoard CFOSAT: Instrument Validation and Ocean Wave Measurement Assessment. IEEE Trans Geosci Remote Sens 1-22. https://doi.org/10.1109/tgrs.2020.2994372

Hithin NK, Remya PG, Balakrishnan Nair TM, et al (2015) Validation and Intercomparison of SARAL/AltiKa and PISTACH-Derived Coastal Wave Heights Using In-Situ Measurements. IEEE J Sel Top Appl Earth Obs Remote Sens 8:4120-4129. https://doi.org/10.1109/JSTARS.2015.2418251

Hoshino S, Esteban M, Mikami T, et al (2016) Estimation of increase in storm surge damage due to climate change and sea level rise in the Greater Tokyo area. Nat Hazards 80:539565. https://doi.org/10.1007/s11069-015-1983-4 
Jiang M, Xu K, Liu Y (2018) Calibration and validation of reprocessed HY-2A altimeter wave height measurements using data from Buoys, Jason-2, Cryosat-2, and SARAL/AltiKa. J Atmos Ocean Technol 35:1331-1352. https://doi.org/10.1175/JTECHD-17-0151.1

Johnson JM, Moore LJ, Ells K, et al (2015) Recent shifts in coastline change and shoreline stabilization linked to storm climate change. Earth Surf Process Landforms 40:569-585. https://doi.org/10.1002/esp.3650

Kazeminezhad MH, Siadatmousavi SM (2017) Performance evaluation of WAVEWATCH III model in the Persian Gulf using different wind resources. Ocean Dyn 67:839-855. https://doi.org/10.1007/s10236-017-1063-2

Kendall M (1975) Rank correlation methods, 4th edn. Griffin, London

Kossin JP, Knapp KR, Olander TL, Velden CS (2020) Global increase in major tropical cyclone exceedance probability over the past four decades. 117:. https://doi.org/10.1073/pnas.1920849117/-/DCSupplemental

Kumar UM, Swain D, Sasamal SK, et al (2015) Validation of SARAL/AltiKa significant wave height and wind speed observations over the North Indian Ocean. J Atmos SolarTerrestrial Phys 135:174-180. https://doi.org/10.1016/j.jastp.2015.11.003

Laloyaux P, de Boisseson E, Balmaseda M, et al (2018) CERA-20C: A Coupled Reanalysis of the Twentieth Century. J Adv Model Earth Syst 10:1172-1195. https://doi.org/10.1029/2018MS001273

Lionello P, Galati MB (2008) Links of the significant wave height distribution in the Mediterranean sea with the Northern Hemisphere teleconnection patterns

Lionello P, Scarascia L (2020) The relation of climate extremes with global warming in the Mediterranean region and its north versus south contrast. Reg Environ Chang 20:. https://doi.org/10.1007/s10113-020-01610-z

Lobeto H, Menendez M, Losada IJ (2021) Future behavior of wind wave extremes due to climate change. Sci Rep 11:7869. https://doi.org/10.1038/s41598-021-86524-4

Mann HB (1945) Nonparametric Tests Against Trend. Econometrica 13:245. https://doi.org/10.2307/1907187 
Mentaschi L, Besio G, Cassola F, Mazzino A (2013) Problems in RMSE-based wave model validations. Ocean Model 72:53-58. https://doi.org/10.1016/j.ocemod.2013.08.003

Mentaschi L, Besio G, Cassola F, Mazzino A (2015) Performance evaluation of Wavewatch III in the Mediterranean Sea. Ocean Model 90:82-94. https://doi.org/10.1016/J.OCEMOD.2015.04.003

Meucci A, Young IR, Aarnes OJ, Breivik Ø (2020) Comparison of wind speed and wave height trends from twentieth-century models and satellite altimeters. J Clim 33:611-624. https://doi.org/10.1175/JCLI-D-19-0540.1

Mori N, Yasuda T, Mase H, et al (2010) Projection of Extreme Wave Climate Change under Global Warming. Hydrol Res Lett 4:15-19. https://doi.org/10.3178/hrl.4.15

Nissen KM, Leckebusch GC, Pinto JG, et al (2010) Natural Hazards and Earth System Sciences Cyclones causing wind storms in the Mediterranean: characteristics, trends and links to large-scale patterns. Hazards Earth Syst Sci 10:1379-1391. https://doi.org/10.5194/nhess-10-1379-2010

Perez J, Menendez M, Camus P, et al (2015) Statistical multi-model climate projections of surface ocean waves in Europe. Ocean Model 96:161-170. https://doi.org/10.1016/J.OCEMOD.2015.06.001

Pisano A, Marullo S, Artale V, et al (2020) New Evidence of Mediterranean Climate Change and Variability from Sea Surface Temperature Observations. Remote Sens 12:132. https://doi.org/10.3390/rs12010132

Poli P, Hersbach H, Dee DP, et al (2016) ERA-20C: An atmospheric reanalysis of the twentieth century. J Clim 29:4083-4097. https://doi.org/10.1175/JCLI-D-15-0556.1

Rani S, Sreekesh S (2018) Variability of Temperature and Rainfall in the Upper Beas Basin, Western Himalaya. pp 101-120

Reguero BG, Losada IJ, Méndez FJ (2019) A recent increase in global wave power as a consequence of oceanic warming. Nat Commun 10:1-14. https://doi.org/10.1038/s41467-018-08066-0

Ribal A, Young IR (2019) 33 years of globally calibrated wave height and wind speed data based on altimeter observations. Sci Data 6:1-15. https://doi.org/10.1038/s41597-0190083-9 
Ris RC, Holthuijsen LH, Booij N (1999) A third-generation wave model for coastal regions: 2. Verification. J Geophys Res 104:7667-7681. https://doi.org/10.1029/1998JC900123

Romera R, Gaertner MÁ, Sánchez E, et al (2017) Climate change projections of medicanes with a large multi-model ensemble of regional climate models. Glob Planet Change 151:134-143. https://doi.org/10.1016/j.gloplacha.2016.10.008

Rusu L, Gonçalves M, Guedes Soares C (2017) Prediction of storm conditions using wind data from the ECMWF and NCEP reanalysis. In: Soares Guedes C, Teixeira Â. (eds) Developments in Maritime Transportation and Harvesting of Sea Resources (2 Volume Set): Proceedings of the 17th International Congress of the International Maritime Association of the Mediterranean (IMAM 2017). Taylor \& Francis Group, 2017, Lisbon, Portugal, p 1278

Saha S, Moorthi S, Pan H-L, et al (2010) The \{NCEP $\}$ Climate Forecast System Reanalysis. Bull Am Meteorol Soc 91:1015-1058. https://doi.org/10.1175/2010BAMS3001.1

Saha S, Moorthi S, Wu X, et al (2014) The \{NCEP $\}$ Climate Forecast System Version 2. J Clim 27:2185-2208. https://doi.org/10.1175/JCLI-D-12-00823.1

Salmi T, Maatta A, Anttila P, et al (2002) Detecting Trends of Annual Values of Atmospheric Pollutants by the Mann-Kendall Test and Sen's Solpe Estimates the Excel Template Application MAKESENS. Finnish Meteorol Institute, Air Qual Res 35

Sánchez E, Gallardo C, Gaertner MA, et al (2004) Future climate extreme events in the Mediterranean simulated by a regional climate model: A first approach. Glob Planet Change 44:163-180. https://doi.org/10.1016/j.gloplacha.2004.06.010

Semedo A, Weisse R, Behrens A, et al (2013) Projection of global wave climate change toward the end of the twenty-first century. J Clim 26:8269-8288. https://doi.org/10.1175/JCLI-D-12-00658.1

Sen PK (1968) Estimates of the Regression Coefficient Based on Kendall's Tau. J Am Stat Assoc 63:1379. https://doi.org/10.2307/2285891

Sobel AH, Tippett MK (2018) Extreme events: trends and risk assessment methodologies. In: Resilience: The Science of Adaptation to Climate Change. Elsevier, pp 3-12

Soukissian T, Karathanasi F, Axaopoulos P, et al (2018) Offshore wind climate analysis and variability in the Mediterranean Sea. Int J Climatol 38:384-402. 
https://doi.org/10.1002/joc.5182

Soukissian T, Karathanasi F, Axaopoulos P (2017) Satellite-Based Offshore Wind Resource Assessment in the Mediterranean Sea. IEEE J Ocean Eng 42:73-86. https://doi.org/10.1109/JOE.2016.2565018

Stopa JE, Cheung KF (2014) Intercomparison of wind and wave data from the ECMWF Reanalysis Interim and the NCEP Climate Forecast System Reanalysis. Ocean Model 75:65-83. https://doi.org/10.1016/j.ocemod.2013.12.006

Stott PA, Gillett NP, Hegerl GC, et al (2010) Detection and attribution of climate change: a regional perspective. Wiley Interdiscip Rev Clim Chang 1:192-211. https://doi.org/10.1002/wcc.34

Taibi H, Haddad M (2019) Estimating trends of the Mediterranean Sea level changes from tide gauge and satellite altimetry data (1993-2015). J Oceanol Limnol 37:1176-1185. https://doi.org/10.1007/s00343-019-8164-3

Tiberi-Wadier A-L, Laugel A, Benoit M (2016) Construction of the Numerical Wave Databases Anemoc-2 on the Mediterranean Sea and the Atlantic Ocean Through Hindcast Simulations Over the Period 1979-2010. In: Advances in Hydroinformatics. Springer, Singapore, pp 127-143

Tuel A, Eltahir EAB (2020) Why is the Mediterranean a Climate Change Hotspot? J Clim JCLI-D-19-0910.1. https://doi.org/10.1175/JCLI-D-19-0910.1

Ulbrich U, May W, Li L, et al (2006) Chapter 8 The Mediterranean climate change under global warming. Dev Earth Environ Sci 4:399-415. https://doi.org/10.1016/S15719197(06)80011-X

Van Vledder GP, Akpınar A (2015) Wave model predictions in the Black Sea: Sensitivity to wind fields. Appl Ocean Res 53:161-178. https://doi.org/10.1016/j.apor.2015.08.006

Vieira F, Cavalcante G, Campos E (2020) Analysis of wave climate and trends in a semienclosed basin (Persian Gulf) using a validated SWAN model. Ocean Eng 196:106821. https://doi.org/10.1016/j.oceaneng.2019.106821

Willmott CJ (1982) Some Comments on the Evaluation of Model Performance 
913 Young IR, Ribal A (2019a) Multiplatform evaluation of global trends in wind speed and wave height. Science (80- ) 364:548-552. https://doi.org/10.1126/science.aav9527

915 Young IR, Ribal A (2019b) Multiplatform evaluation of global trends in wind speed and wave 916 height Tropical Cyclones View project Wave energy resource assessments View project. https://doi.org/10.1126/science.aav9527

Young IR, Zieger S, Babanin A V. (2011) Global trends in wind speed and wave height. Science (80- ) 332:451-455. https://doi.org/10.1126/science.1197219

Yuchun LIN, Leo OEY (2020) Global trends of sea surface gravity wave, wind, and coastal wave setup. J Clim 33:769-785. https://doi.org/10.1175/JCLI-D-19-0347.1 Aug 2020 


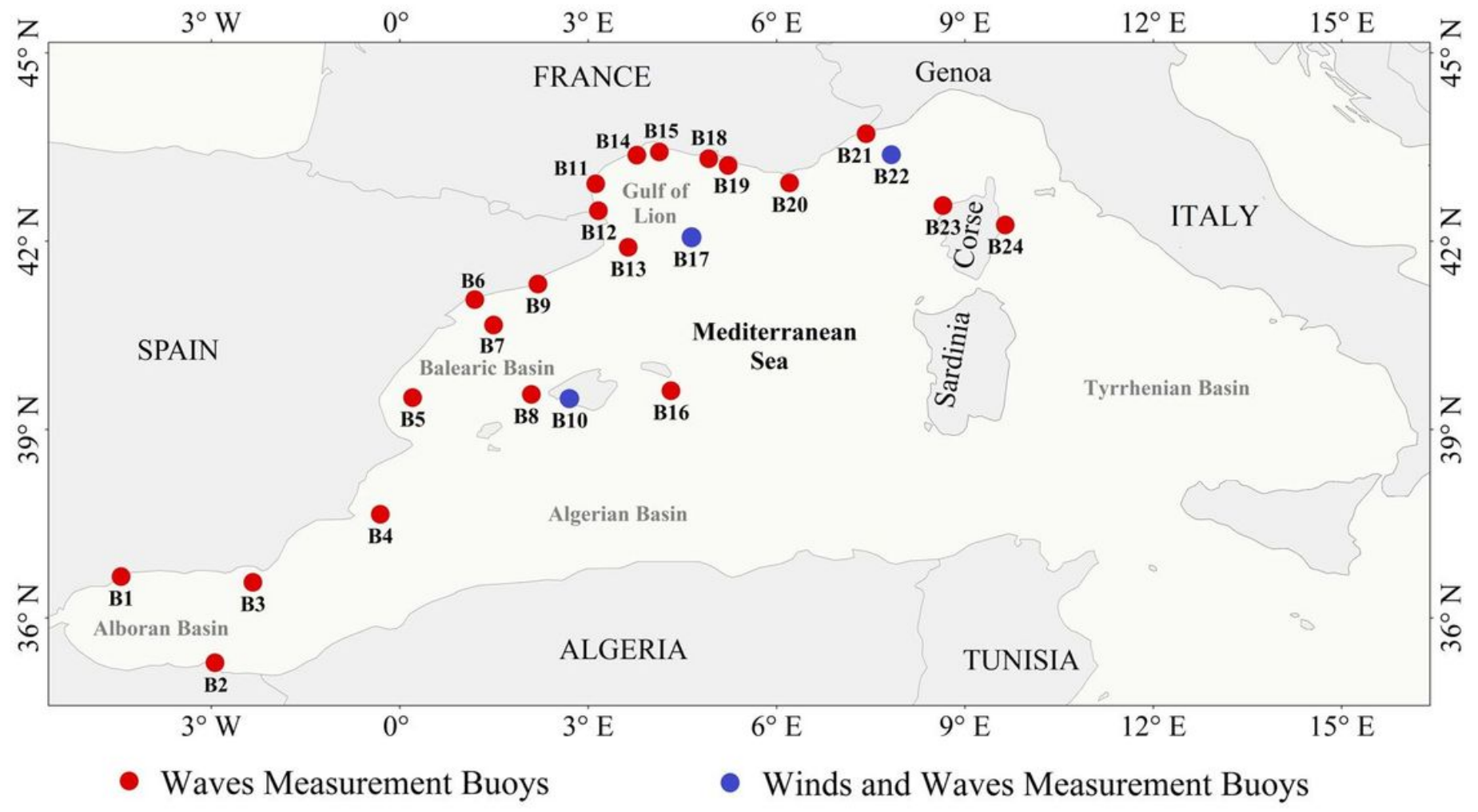

\section{Figure 1}

The locations of wave and wind buoy measurements
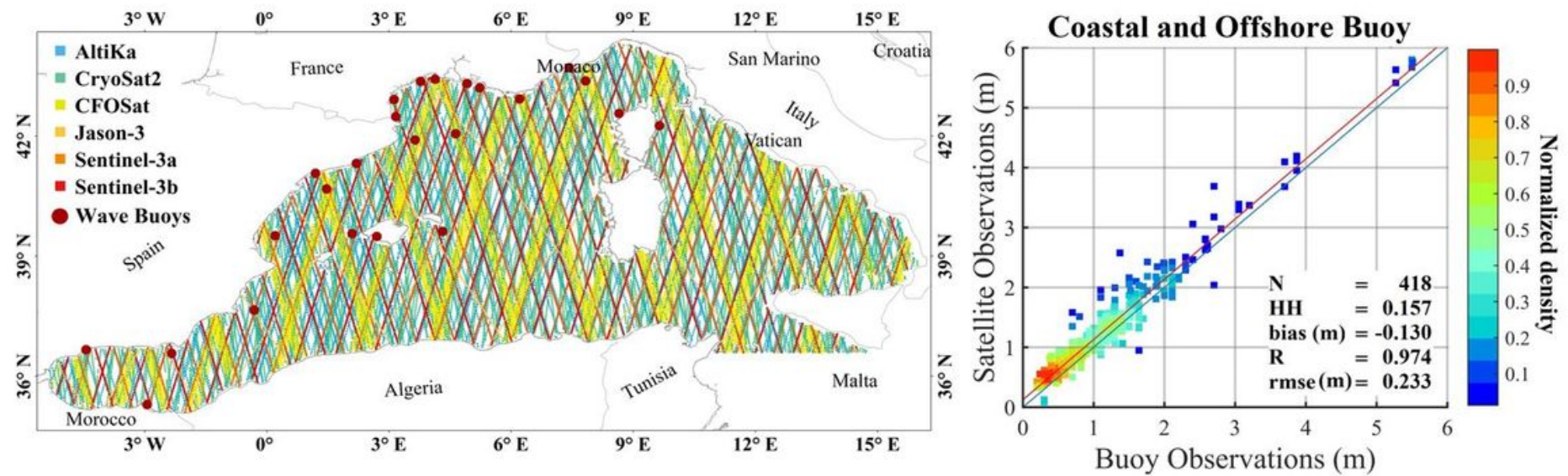

Figure 2

The map of satellites observations used for the spatial validation of the wave hindcast data, showing the position of the wave buoy used for the satellite data accuracy assessment (left), and a Density scatter 
plot with error statistics obtained by comparing the satellite observations against the buoys measurement (right); the color bar indicates the normalized density of observations in the scatter plot.

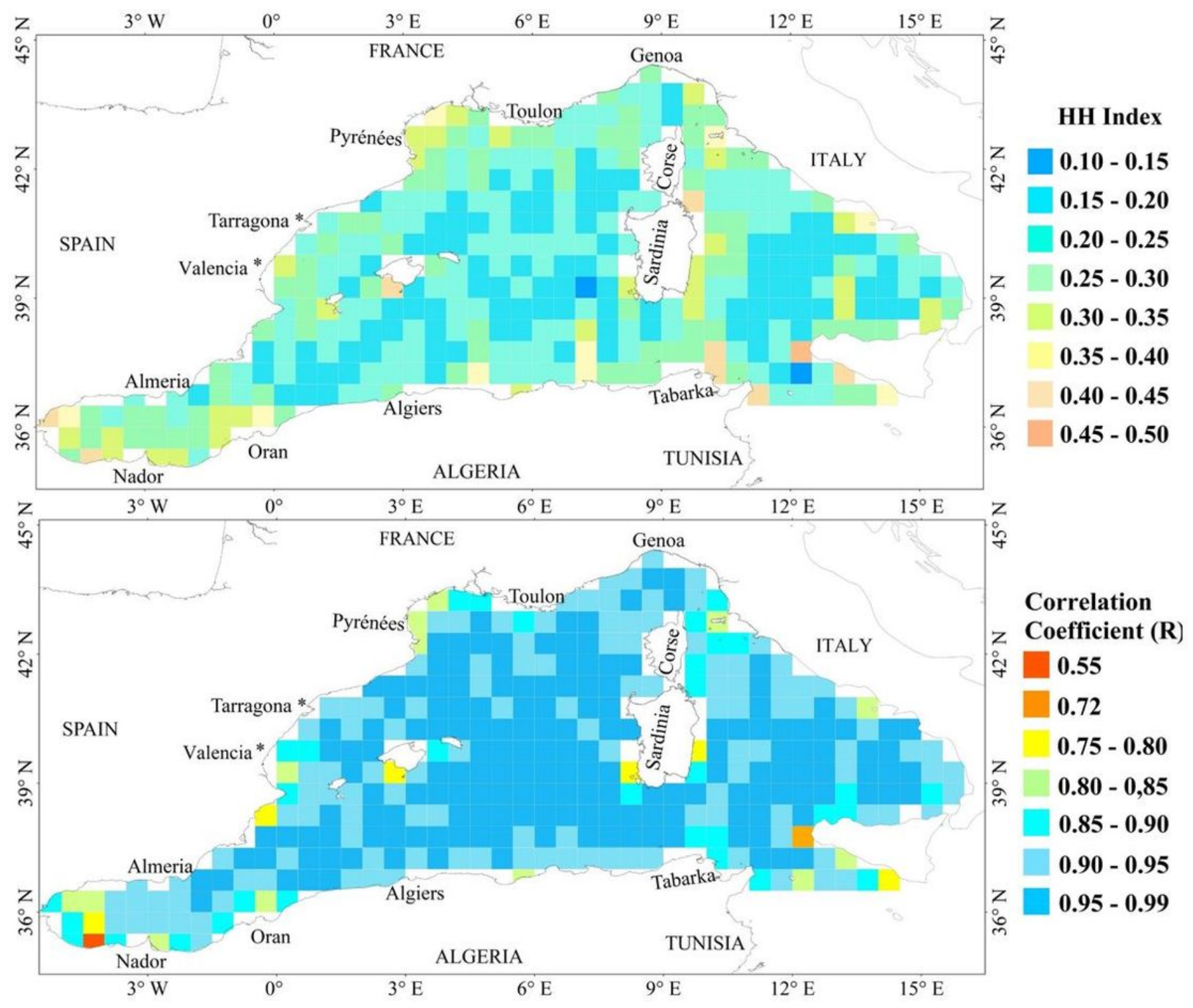

Figure 3

Spatial distribution of the error indicator $\mathrm{HH}$ index and the correlation coefficient $\mathrm{R}$ obtained by comparing the SWH results of the SWAN model with satellite measurements between July 2019 and March 2020. 

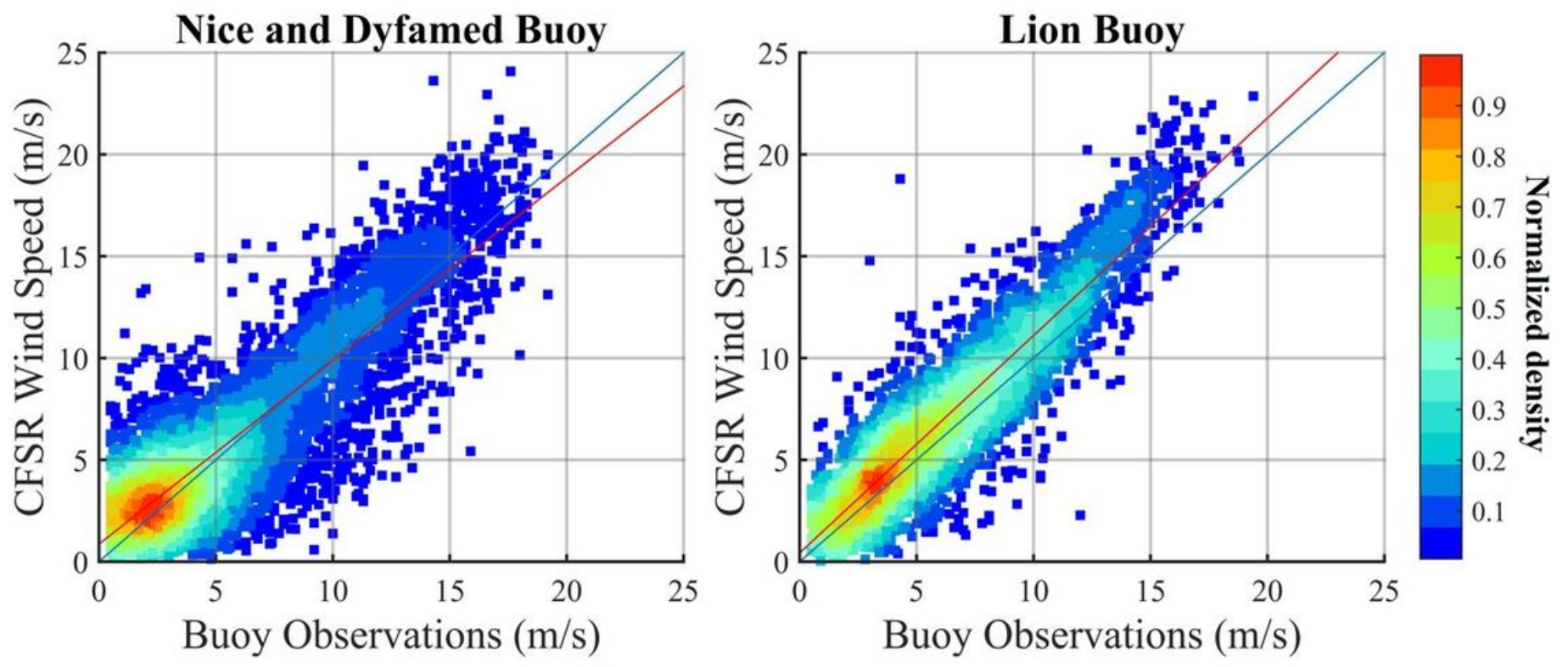

Figure 4

Scatter plot of CFSR wind speed versus observed wind speed at Nice and Lion Buoys between July 2019 and March 2020. The color bar indicates the normalized density of observations in the scatter plots.
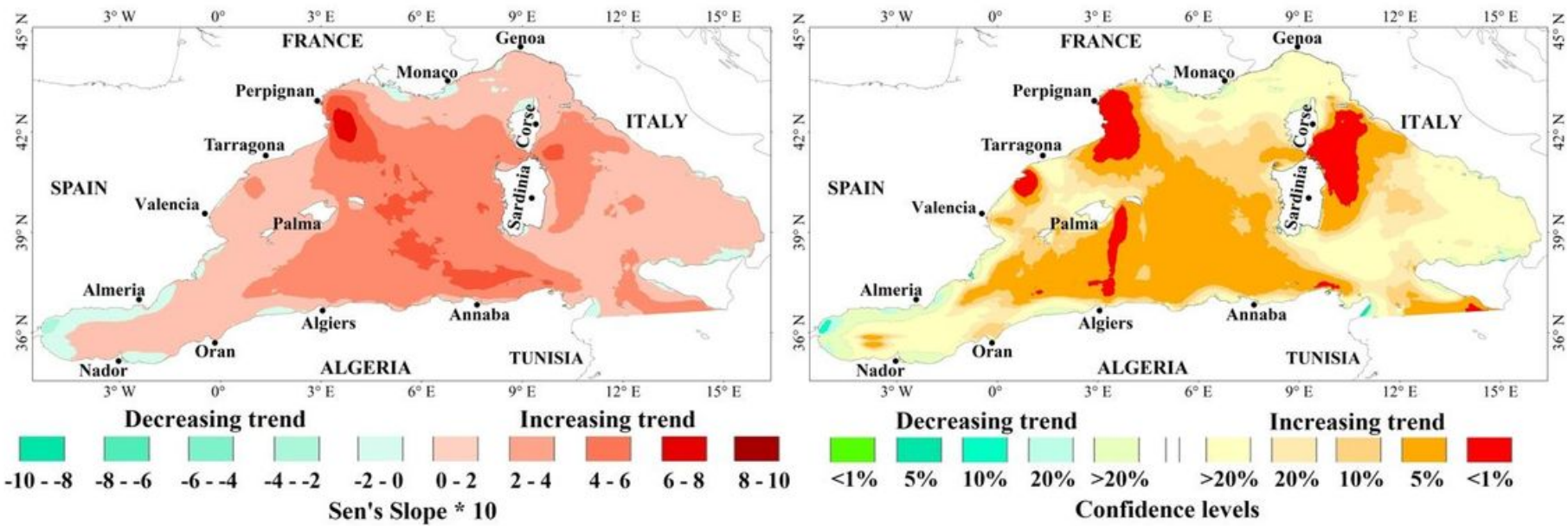

$$
\text { Decreasing trend Increasing trend }
$$
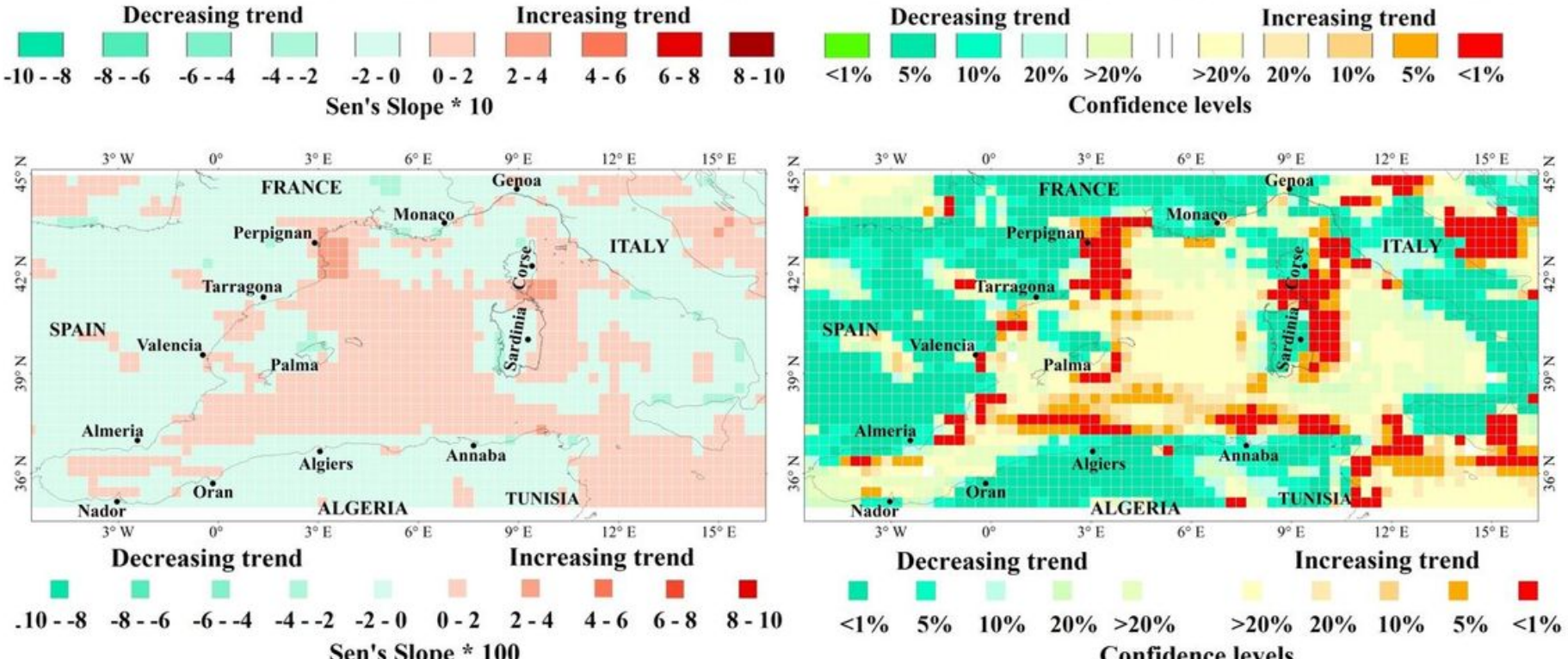
Confidence levels 


\section{Figure 5}

Spatial distribution of Theil-Sen slope estimates (left column) and the significance (right column) of longterm trends according to the Mann Kendall Test at different confidence levels for both annual SWH_Mean [cm/year] (upper panel) and annual WS_Mean [cm.s-1/year] (lower panel).
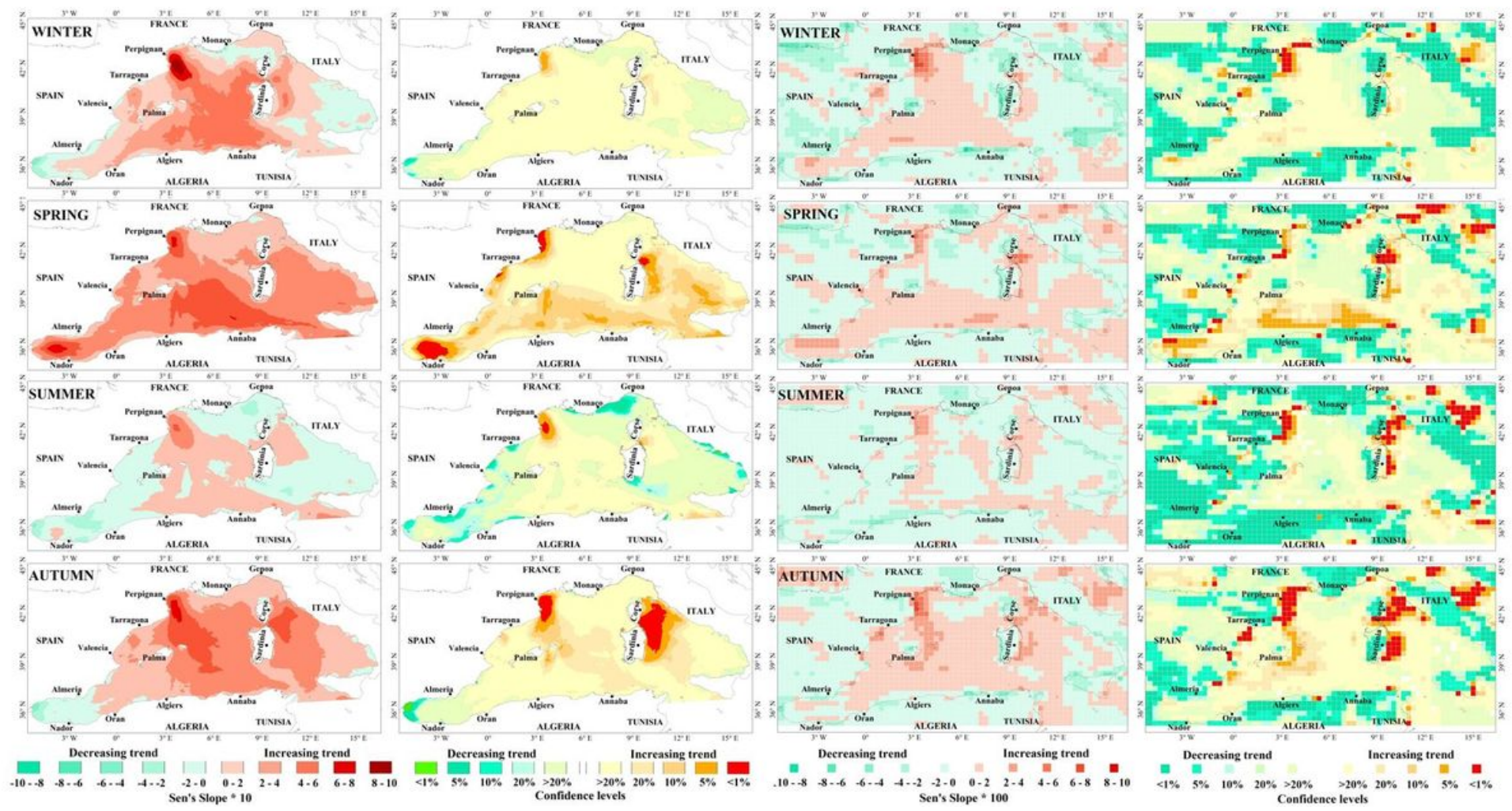

Figure 6

Spatial distribution of Theil-Sen slope estimates (the first and third columns) and the significance (the second and fourth columns) of long-term trends according to the Mann Kendall Test at different confidence levels for both seasonal SWH_Mean [cm/year] (the first two columns) and seasonal WS_Mean [cm.s-1/year] (the last two columns). 

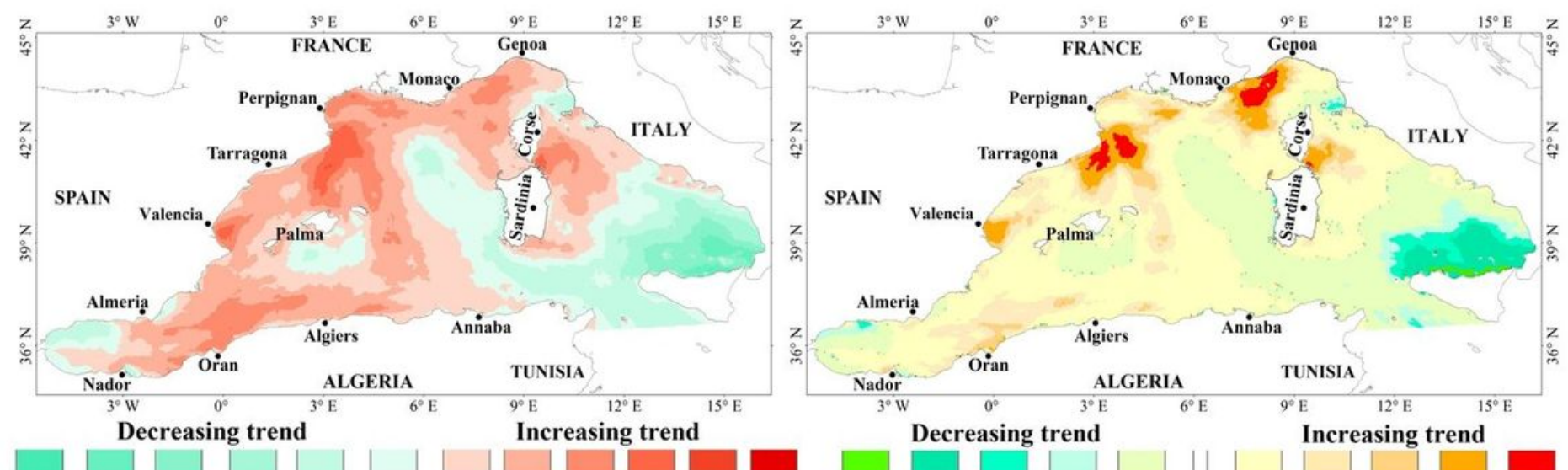

$-6--5-5--4-4--3-3--2-2--1-1-0 \quad 0-1 \quad 1-2 \quad 2-3 \quad 3-4 \quad 4-5$ - $5-6$ Sen's Slope

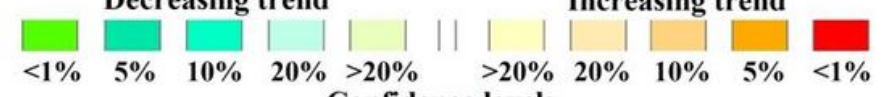

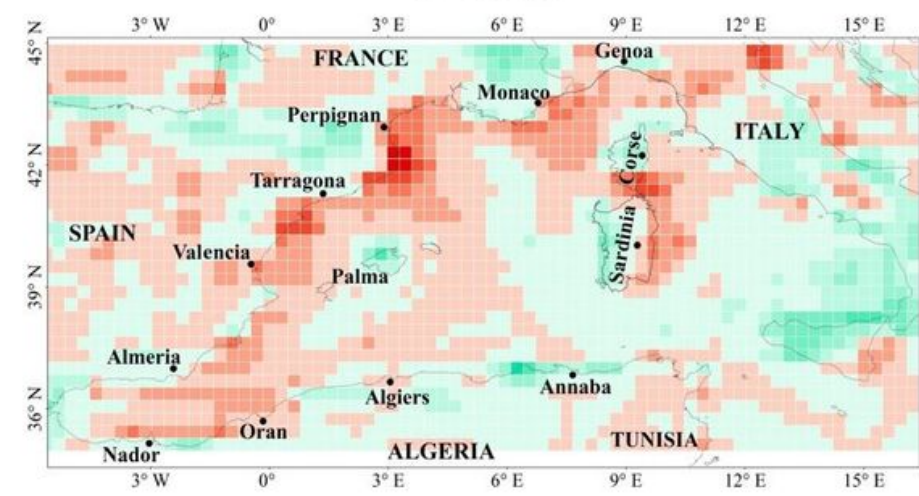

Decreasing trend
Increasing trend

$-20--16-16--12-12--8 \quad-8--4-4-0 \quad 0-4 \quad 4-8 \quad 8-12 \quad 12-16 \quad 16-20$ Sen's Slope * 100

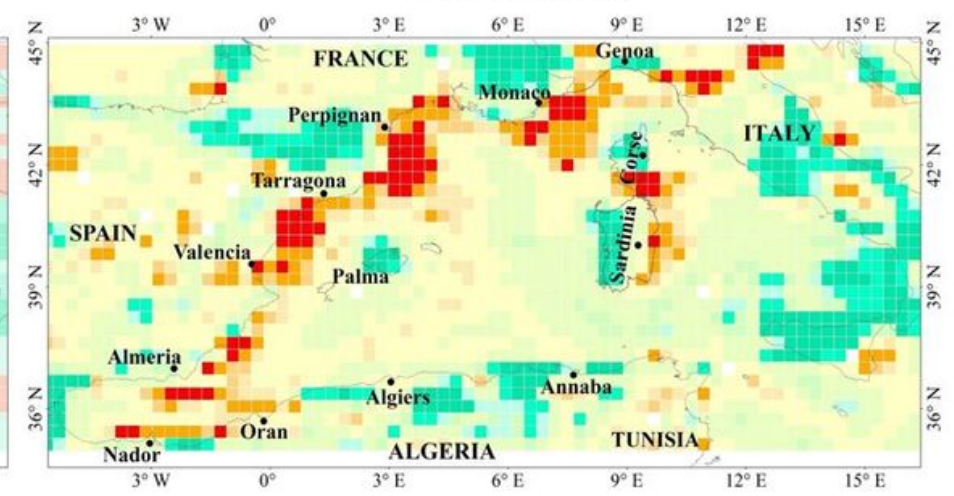

Decreasing trend
Increasing trend

$\begin{array}{llllllllll}<1 \% & 5 \% & 10 \% & 20 \% & >20 \% & >20 \% & 20 \% & 10 \% & 5 \% & <1 \%\end{array}$ Confidence levels

Figure 7

Spatial distribution of Theil-Sen slope estimates (left column) and the significance (right column) of longterm trends according to the Mann Kendall Test at different confidence levels for both annual SWH_Max [cm/year] (upper panel) and annual WS_Max [cm.s-1/year] (lower panel). 


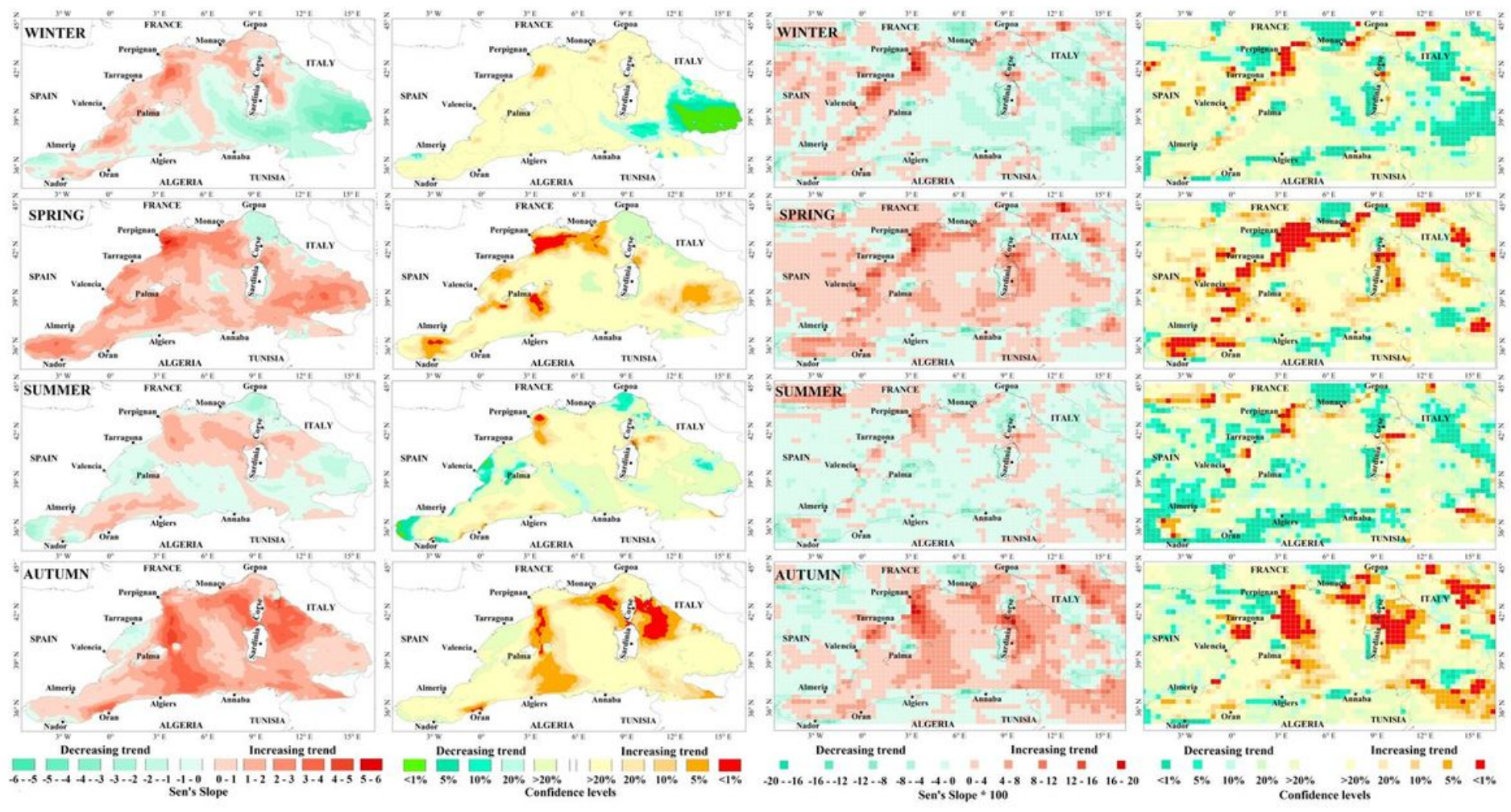

\section{Figure 8}

Spatial distribution of Theil-Sen slope estimates (the first and third columns) and the significance (the second and fourth columns) of long-term trends according to the Mann Kendall Test at different confidence levels for both seasonal SWH_Max [cm/year] (the first two columns) and seasonal WS_Max [cm.s-1/year] (the last two columns). 

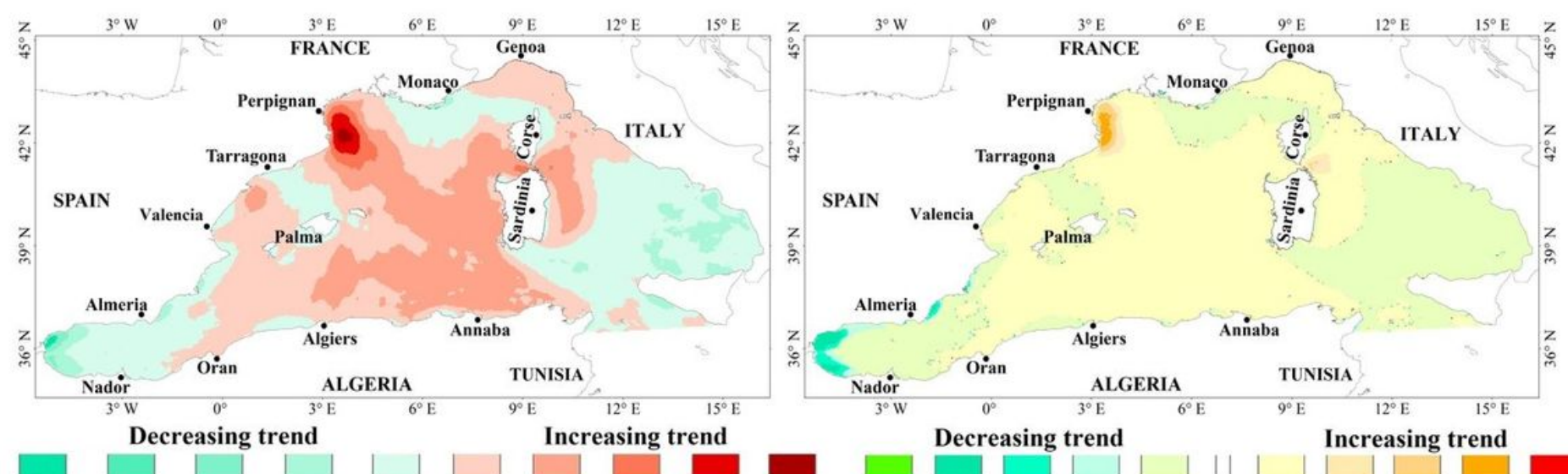

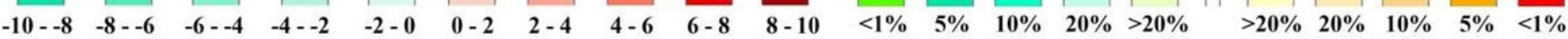
Sen's Slope * 10

Confidence levels

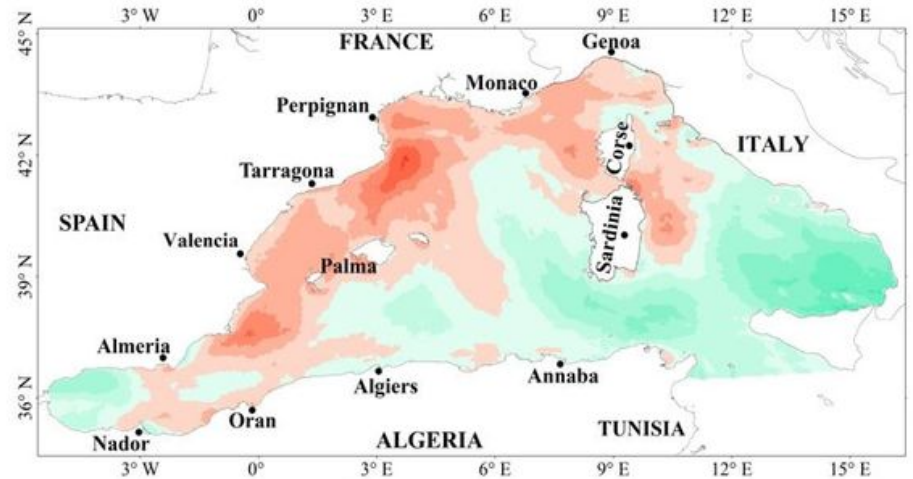

Decreasing trend
Increasing trend

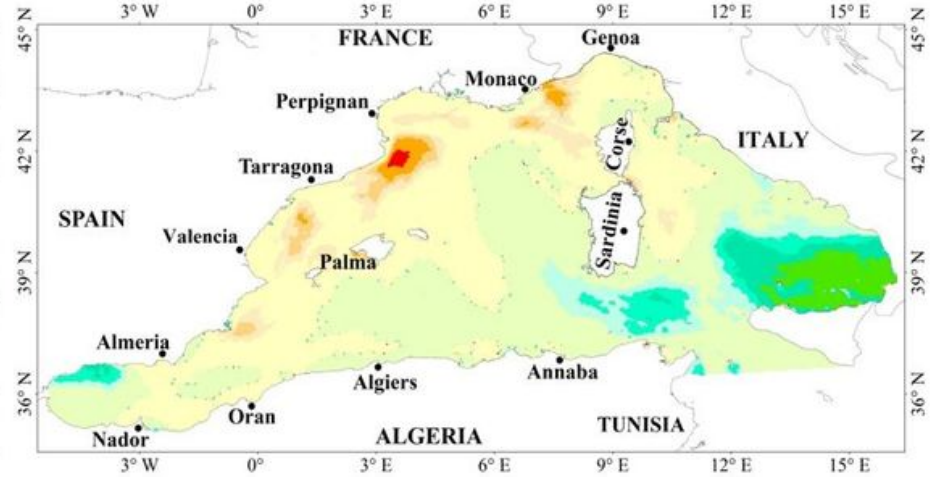

Decreasing trend
Increasing trend

$-6--5-5--4-4--3-3--2-2--1-1-0 \quad 00-1 \quad 1-2 \quad 2-3 \quad 3-4 \quad 4-5 \quad 5-6$ Sen's Slope

$\begin{array}{llllllllll}<1 \% & 5 \% & 10 \% & 20 \% & >20 \% & >20 \% & 20 \% & 10 \% & 5 \% & <1 \%\end{array}$ Confidence levels

\section{Figure 9}

Spatial distribution of Theil-Sen slope estimates (left column) and the significance (right column) of longterm trends (1979 to 2020) according to the Mann Kendall Test at different confidence levels for winters SWH_Mean [cm/year] (the first row) and for winters SWH_Max [cm/year] (the second row).

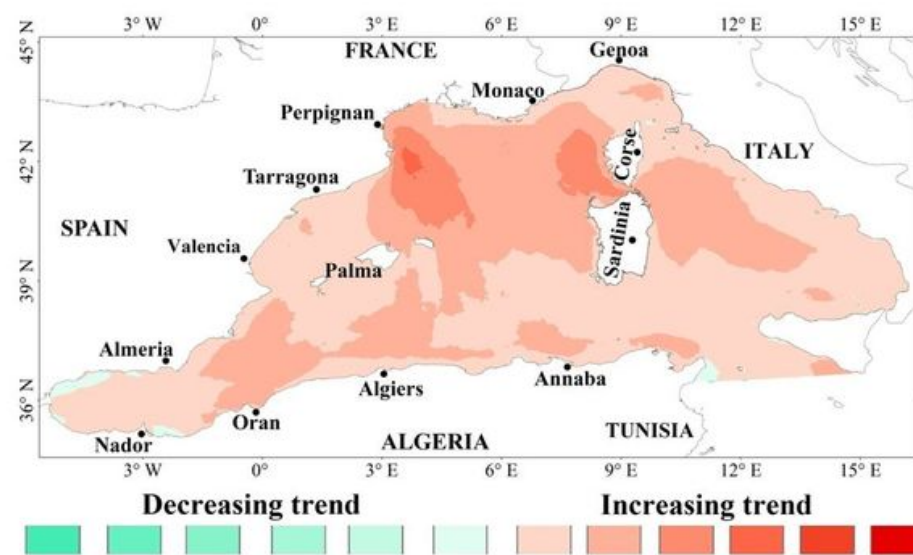

$-6--5-5--4-4--3-3--2-2--1-1-0 \quad 0-1 \quad 1-2 \quad 2-3 \quad 3-4 \quad 4-5 \quad 5-6$ Sen's Slope

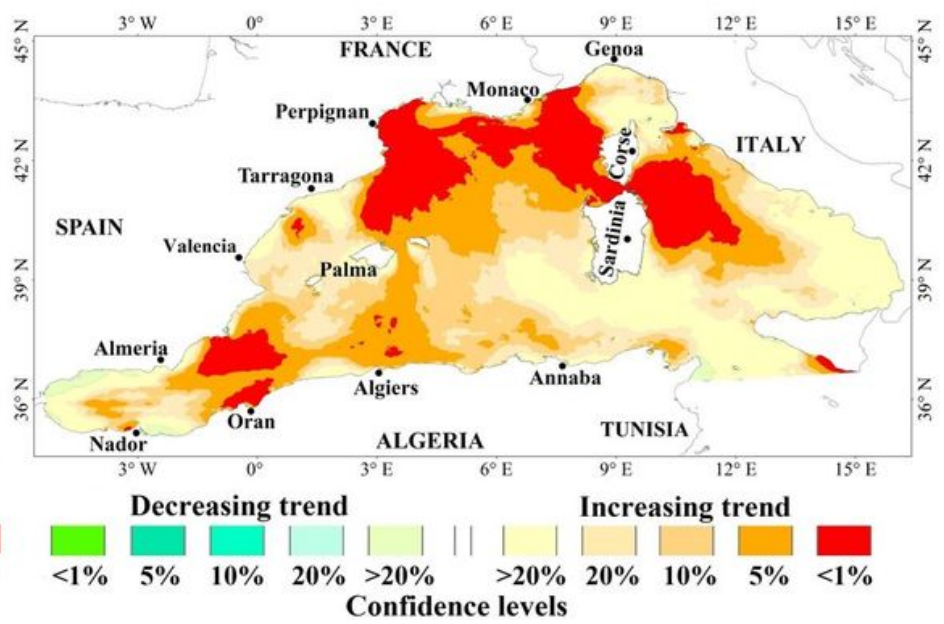

Confidence levels 
Spatial distributions of long-term trends Theil-Sen slope in [cm/year] of the annual average of monthly SWH-max and their significant trends according to the Mann Kendall Test at different confidence levels.

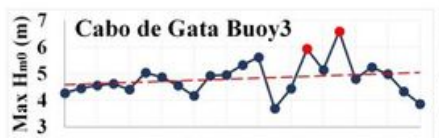

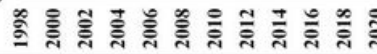

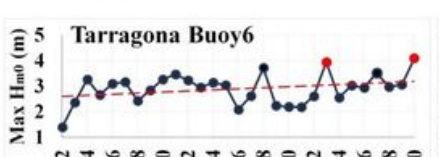

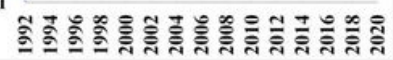
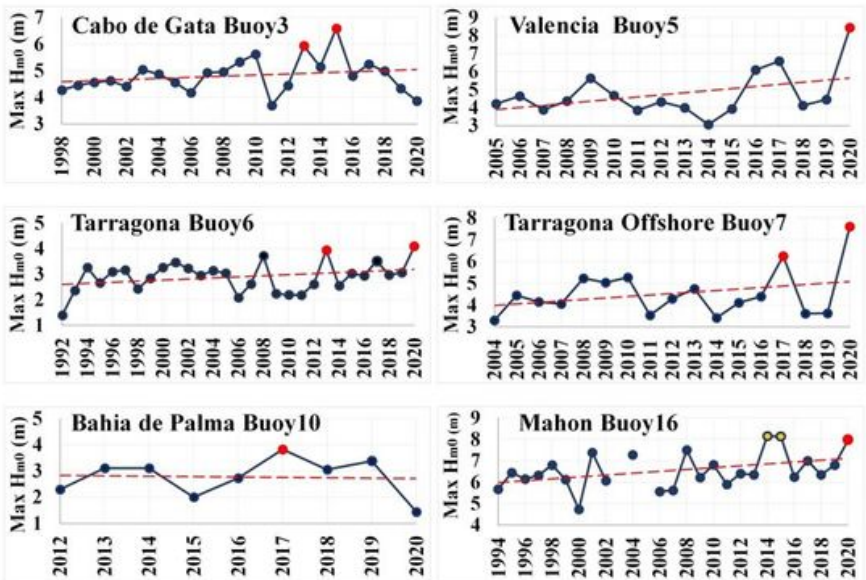

3.
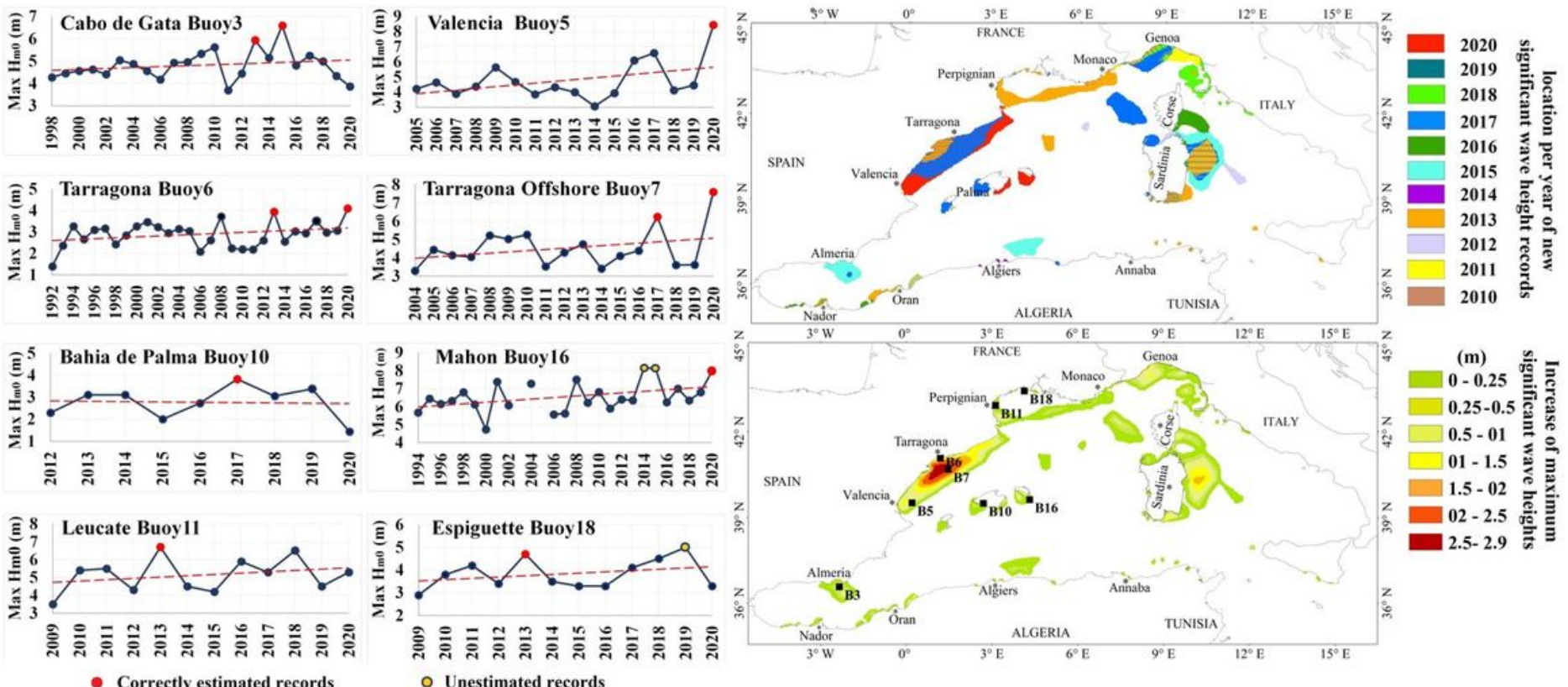

- Correctly estimated records

○ Unestimated records

\section{Figure 11}

Spatial distributions of the annual new records of SWH between January 2010 and 2020 (the right plot in the upper panel) and the differences between the maximum SWH observed from 2010 to 2020 and those observed from 1979 to 2010 (the right plot in the lower panel) and time series plots of the annual maximum SWH observed by six buoys located in the new records areas (the left two columns). 